\title{
Modeling antibiotic and cytotoxic effects of the dimeric isoquinoline IQ-143 on metabolism and its regulation in Staphylococcus aureus, Staphylococcus epidermidis and human cells
}

\author{
Alexander Cecil ${ }^{1 \dagger}$, Carina Rikanović ${ }^{2 \dagger}$, Knut Ohlsen ${ }^{3 \dagger}$, Chunguang Liang ${ }^{1}$, Jörg Bernhardt ${ }^{4}$, Tobias A Oelschlaeger $^{3}$,
} Tanja Gulder ${ }^{5,6}$, Gerhard Bringmann" ${ }^{5}$ Ulrike Holzgrabe ${ }^{2}$, Matthias Unger ${ }^{2}$ and Thomas Dandekar , $^{1 *}$

\begin{abstract}
Background: Xenobiotics represent an environmental stress and as such are a source for antibiotics, including the isoquinoline (IQ) compound IQ-143. Here, we demonstrate the utility of complementary analysis of both host and pathogen datasets in assessing bacterial adaptation to IQ-143, a synthetic analog of the novel type N,C-coupled naphthyl-isoquinoline alkaloid ancisheynine.

Results: Metabolite measurements, gene expression data and functional assays were combined with metabolic modeling to assess the effects of IQ-143 on Staphylococcus aureus, Staphylococcus epidermidis and human cell lines, as a potential paradigm for novel antibiotics. Genome annotation and PCR validation identified novel enzymes in the primary metabolism of staphylococci. Gene expression response analysis and metabolic modeling demonstrated the adaptation of enzymes to IQ-143, including those not affected by significant gene expression changes. At lower concentrations, IQ-143 was bacteriostatic, and at higher concentrations bactericidal, while the analysis suggested that the mode of action was a direct interference in nucleotide and energy metabolism. Experiments in human cell lines supported the conclusions from pathway modeling and found that IQ-143 had low cytotoxicity.

Conclusions: The data suggest that IQ-143 is a promising lead compound for antibiotic therapy against staphylococci. The combination of gene expression and metabolite analyses with in silico modeling of metabolite pathways allowed us to study metabolic adaptations in detail and can be used for the evaluation of metabolic effects of other xenobiotics.
\end{abstract}

\section{Background}

Antibiotic treatment of infectious diseases has become increasingly challenging as pathogenic bacteria have acquired a broad spectrum of resistance mechanisms. In particular, the emergence and spread of multi-resistant staphylococci has progressed to a global health threat [1]. They are not only resistant to almost all treatments, but also adapt very well to different conditions in the host, including persistence [2-4]. In the face of

\footnotetext{
* Correspondence: dandekar@biozentrum.uni-wuerzburg.de

+ Contributed equally

'University of Würzburg, Theodor-Boveri Institute, Department of

Bioinformatics, Am Hubland, 97074 Würzburg, Germany

Full list of author information is available at the end of the article
}

increasing resistance against antibiotics as well as persistence of staphylococci in the patient, an intensive search of new antibacterial lead compounds addressing new targets is urgently required.

Currently, several '-omics' techniques are available, but they are expensive and, in general, only limited information is available for each type of data [5]. We will show how different data sets for studying the metabolic effects of a xenobiotic can be efficiently combined to derive a maximum of information utilizing pathway modeling [6-8] while validating the latter by experimental data.

A new emerging paradigm for investigating drug effects and toxicity is followed here: instead of considering the body of the studied organism as a black box and

\section{C) Biomed Central}


just identifying toxic or antibiotic concentrations, genomics and post-genomics strategies are used to reveal affected pathways. This combination enables a more rapid understanding of metabolic effects and at the same time also reveals side effects in unprecedented detail, leading to a network paradigm: a substance is not just toxic or nontoxic but has, in general, stronger or weaker and concentration-dependent network effects.

In our studies we observed a drastic change in metabolic activity after administration of the isoquinolinium salt IQ-143 (Figure 1) and show for staphylococci that this compound is a xenobiotic with antibiotic properties. IQ-143 constitutes a structurally simplified analogue of a new subclass of bioactive natural products, the $N, C$ coupled naphthylisoquinoline alkaloids, which were first isolated from tropical lianas belonging to the Ancistrocladaceae plant family. Representatives of these alkaloids, such as ancistrocladinium $\mathrm{A}$ and $\mathrm{B}$, exhibit excellent antiinfective activities - for example, against the pathogen Leishmania major - and thus serve as promising lead structures for the treatment of severe infectious diseases [9-13]. This class of compounds comprises complex natural products and newly developed synthetic analogues thereof [14-16] and provides a rich repertoire of representatives with a large potential against a number of infectious diseases, but potentially also bears the risk of toxic effects in humans.

Starting from publicly available genome sequences $[17,18]$, genome annotation in the staphylococci strains was completed by sequence and domain analysis [19] to identify several previously unidentified metabolic enzymes of their central metabolism. The respective bioinformatic results obtained were validated by PCR analysis. The obtained gene expression data helped to monitor in detail the effect of different concentrations of the isoquinoline on staphylococci. Also, the combination with metabolic modeling allowed us to fill in missing information on all central metabolic enzymes,

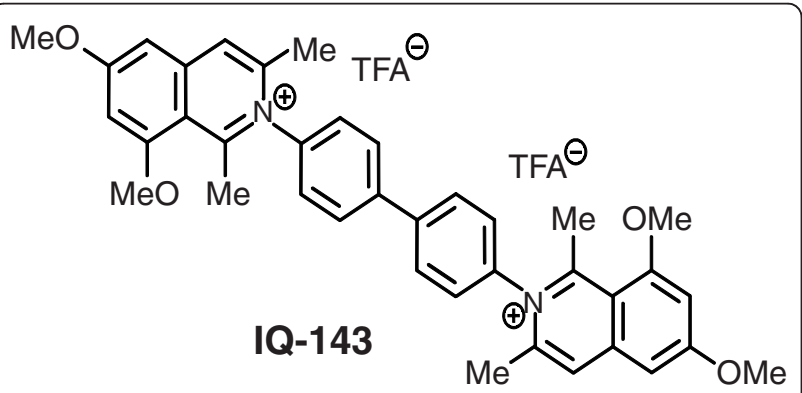

Figure 1 Structure of IQ-143. Shown is the structure of the environmental challenge and xenobiotic chosen, isoquinolinium salt IQ-143, a structurally simplified analogue of a new subclass of bioactive natural products, the N,C-coupled naphthyl-isoquinolines alkaloids. including those not affected by significant gene expression changes, and to obtain a complete view of the resulting metabolic adaptations of the staphylococci. These genome-scale predictions were further validated by direct metabolite measurements on specific nucleotides.

In general, the pathway modeling allows one to consider network effects besides target effects (for instance, on glycolysis, which decreases with increasing IQ-143 concentrations but is not a direct target of IQ-143) and to find areas that are comparatively resistant (for example, the pentose phosphate pathway). Gene expression data are complemented by the network modeling and from these counter regulation by higher gene expression can be identified. Only a few metabolite measurements are sufficient to validate the predictions regarding the involved pathways - for example, here regarding nucleotides as well as nucleotide-containing cofactors. We tested the independence of the data sets carefully and used them to also cross-validate the modeled pathway fluxes - for example, whether the network predictions from gene expression data fit measured nucleotide concentrations.

Metabolic responses in human cells were modeled considering measurements on cytochrome P450 (CYP) detoxification data. We extrapolated again for all effects on central pathways and compared the resulting predictions to cytotoxicity data on human cells.

\section{Results}

IQ-143 added to a Staphylococcus epidermidis culture: gene expression changes and metabolic model

IQ-143 has been identified by structure-activity relationship studies in a screening program for compounds with anti-staphylococcal activity [20]. To get a first hint of the mode of action of this substance, DNA-microarray experiments were conducted. The clinical S. epidermidis strain RP62A was grown in the presence of IQ-143 (concentrations of a quarter of the minimum inhibitory concentration and twice the minimum inhibitory concentration) as described in the Materials and methods section and hybridized to full genome arrays. Significant gene expression differences for S. epidermidis are shown in Tables 1 and 2 (details shown in Additional file 1: Table S5 lists gene expression differences for $1.25 \mu \mathrm{M}$ of IQ-143, Table S6 for $0.16 \mu \mathrm{M}$ of IQ-143). Overall, the expression of genes encoding proteins involved in the transport of macromolecules, such as the ATP-binding cassette $(A B C)$ transporter, the peptide transporter, and the choline transporter, and metabolic enzymes of carbohydrate pathways were especially significantly affected.

To analyze pathway changes resulting from the mode of action of IQ-143, including identification of affected 
Table 1 Gene expression changes measured after administration of IQ-143 in S. epidermidis RP62A

\begin{tabular}{|c|c|c|c|}
\hline \multirow[b]{2}{*}{ Affected enzymes } & \multicolumn{3}{|c|}{ Gene expression after IQ-143 administration } \\
\hline & $0.00 \mu \mathrm{M}^{\mathrm{a}}$ & $0.16 \mu \mathrm{M}$ & $1.25 \mu \mathrm{M}$ \\
\hline OP_complex1 & 1.000 & 1.000 & 1.000 \\
\hline OP_complex2 & 1.000 & 1.000 & 1.000 \\
\hline OP_complex3 & 1.000 & 1.000 & 8.390 \\
\hline OP_complex4 & 1.000 & 1.000 & 1.000 \\
\hline OP_complex5a & 1.000 & 1.000 & 1.000 \\
\hline SERP0290-zinc-transport_efflux & 1.000 & 0.399 & 0.449 \\
\hline SERP0291-zinc-transporter_import & 1.000 & 0.544 & 0.450 \\
\hline SERP0292-iron-dicitrate-transporter_import & 1.000 & 0.544 & 0.430 \\
\hline SERP0389-EC:1.1.1.1-rn:R00754 & 1.000 & 1.000 & 3.070 \\
\hline SERP0653-EC:6.3.5.3-rn:R04463 & 1.000 & 1.000 & 0.491 \\
\hline SERP0655-EC:2.4.2.14-rn:R01072 & 1.000 & 1.000 & 0.436 \\
\hline SERP0656-EC:6.3.3.1-rn:R04208 & 1.000 & 1.000 & 0.424 \\
\hline SERP0657-EC:2.1.2.2-rn:R04325 & 1.000 & 1.000 & 0.426 \\
\hline SERP0658-EC:2.1.2.3-rn:R04560 & 1.000 & 1.000 & 0.439 \\
\hline SERP0659-EC:6.3.4.13-rn:R04144 & 1.000 & 1.000 & 0.392 \\
\hline SERP0686-spermidine/putrescine-transport_import & 1.000 & 1.000 & 2.361 \\
\hline SERP0687-spermidine/putrescine-transport_import & 1.000 & 1.000 & 2.208 \\
\hline SERP0688-spermidine/putrescine-transport_import & 1.000 & 1.000 & 2.075 \\
\hline SERP0765-Uracil-permease-transport_import & 1.000 & 1.000 & 2.765 \\
\hline SERP0831-EC:2.7.7.7-rn:R00375 & 1.000 & 1.000 & 2.202 \\
\hline SERP0831-EC:2.7.7.7-rn:R00376 & 1.000 & 1.000 & 2.202 \\
\hline SERP0831-EC:2.7.7.7-rn:R00378 & 1.000 & 1.000 & 2.202 \\
\hline SERP0831-EC:2.7.7.7-rn:R00379 & 1.000 & 1.000 & 2.202 \\
\hline SERP0841-EC:2.7.7.8-rn:R00437 & 1.000 & 1.000 & 2.867 \\
\hline SERP0841-EC:2.7.7.8-rn:R00439 & 1.000 & 1.000 & 2.867 \\
\hline SERP1403-MultiDrug-transport_efflux & 1.000 & 1.000 & 2.063 \\
\hline SERP1802-cobalt/nickel-transport_efflux & 1.000 & 1.000 & 2.401 \\
\hline SERP1803-cobalt/nickel-transport_efflux & 1.000 & 1.000 & 2.301 \\
\hline SERP1944-MultiDrug-transport_efflux & 1.000 & 1.000 & 2.075 \\
\hline SERP1951-lipoprotein-transport_efflux/import & 1.000 & 1.000 & 0.457 \\
\hline SERP1952-macrolide-transport_efflux & 1.000 & 1.000 & 0.386 \\
\hline SERP1997-formate/nitrite-transport_efflux/import & 1.000 & 1.000 & 2.619 \\
\hline SERP2060-glyerol-transport_import & 1.000 & 1.000 & 2.823 \\
\hline SERP2156-EC:1.1.1.27-rn:R00703 & 1.000 & 1.000 & 0.486 \\
\hline SERP2179-choline/betaine/carnitine-transp_efflux & 1.000 & 7.071 & 2.389 \\
\hline SERP2186-EC:2.7.7.4-rn:R00529 & 1.000 & 1.000 & 0.349 \\
\hline SERP2283-phopsphonate-transport_import & 1.000 & 1.000 & 2.680 \\
\hline SERP2289-MultiDrug-transport_efflux & 1.000 & 1.000 & 1.971 \\
\hline
\end{tabular}

This table shows the gene expression changes measured after administration of IQ-143. 1.0 denotes the standard activity without IQ-143. A value of 0.5 indicates that the activity of this enzyme was halved after administration of IQ-143, a value of 2.075 indicates that the activity was doubled (again after administration of IQ-143). ${ }^{a}$ Expression with no IQ-143 (0.00 $\mu \mathrm{M}$ column) is set to 1.000 for normalization purposes.

enzymes that are not already apparent from the transcriptome data, we applied YANAsquare $[21,22]$ and a custom-made routine written in $\mathrm{R}$ [23] for calculating metabolic-flux changes after administration of IQ-143 (Figures 2 and 3).

The calculation of the pathway changes started from the metabolic model of $S$. epidermidis (details in Table S3 in Additional file 1) and applied the gene expression data with significant expression changes (Table 1) as flux constraints (Tables S10, S11 and S12 in Additional file 1; detailed changes in Tables S16 and S17 in Additional file 1).

We first prepared a stoichiometric matrix in which the rows and columns correspond to all the enzymes (for annotation and collection see next chapter in results and Materials and methods) in the network as well as the internal metabolites of the network. The 'internal' metabolites inside the network have to be balanced: 
Table 2 Key effects of the measured gene expression differences after administration of IQ-143 compared to untreated S. epidermidis RP62A

\begin{tabular}{|c|c|c|c|}
\hline Concentration of IQ-143 ( $\mu \mathrm{M})$ & Enzymes affected $^{\mathrm{a}}$ & Effect on enzymes $^{\mathbf{b}}$ & Phenotypic effects $^{c}$ \\
\hline \multirow[t]{4}{*}{$0.16 \mu \mathrm{M}$} & SERP0290-zinc-transport_efflux & Down-regulated & \\
\hline & SERP0291-zinc-transporter_import & Down-regulated & $40 \%$ biofilm inhibition \\
\hline & SERP0292-iron-dicitrate-transporter_import & Down-regulated & No growth inhibition \\
\hline & SERP2179-choline/betaine/carnitine-transp_efflux & Up-regulated & \\
\hline \multirow[t]{31}{*}{$1.25 \mu \mathrm{M}$} & SERP0290-zinc-transport_efflux & Down-regulated & \\
\hline & SERP0291-zinc-transporter_import & Down-regulated & \\
\hline & SERP0292-iron-dicitrate-transporter_import & Down-regulated & \\
\hline & SERP0653-FGAM synthetase-rn:R04463 & Down regulated & \\
\hline & SERP0655-amidophosphoribosyltransferase-rn:R01072 & Down-regulated & \\
\hline & SERP0656-AIR synthetase-rn:R04208 & Down-regulated & \\
\hline & SERP0657-GAR formyltransferase-rn:R04325 & Down-regulated & \\
\hline & SERP0658-AICAR transformylase-rn:R04560 & Down-regulated & $\sim 100 \%$ biofilm inhibition \\
\hline & SERP0659-glycinamide ribonucleotide synthetase-rn:R04144 & Down-regulated & $\sim 100 \%$ growth inhibition \\
\hline & SERP0686-spermidine/putrescine-transport_import & Up-regulated & \\
\hline & SERP0687-spermidine/putrescine-transport_import & Up-regulated & \\
\hline & SERP0688-spermidine/putrescine-transport_import & Up-regulated & \\
\hline & SERP0765-Uracil-permease-transport_import & Up-regulated & \\
\hline & SERP0831-DNA polymerase-rn:R00375 & Up-regulated & \\
\hline & SERP0831-DNA polymerase-rn:R00376 & Up-regulated & \\
\hline & SERP0831-DNA polymerase-rn:R00378 & Up-regulated & \\
\hline & SERP0831-DNA polymerase-rn:R00379 & Up-regulated & \\
\hline & SERP0841-PNPase-rn:R00437 & Up-regulated & \\
\hline & SERP0841-PNPase-rn:R00439 & Up-regulated & \\
\hline & SERP1403-MultiDrug-transport_efflux & Up-regulated & \\
\hline & SERP1802-cobalt/nickel-transport_efflux & Up-regulated & \\
\hline & SERP1803-cobalt/nickel-transport_efflux & Up-regulated & \\
\hline & SERP1944-MultiDrug-transport_efflux & Up-regulated & \\
\hline & SERP1951-lipoprotein-transport_efflux/import & Down-regulated & \\
\hline & SERP1952-macrolide-transport_efflux & Down-regulated & \\
\hline & SERP1997-formate/nitrite-transport_efflux/import & Up-regulated & \\
\hline & SERP2060-glyerol-transport_import & Up-regulated & \\
\hline & SERP2179-choline/betaine/carnitine-transp_efflux & Up-regulated & \\
\hline & SERP2186-ATP-sulfurylase;-rn:R00529 & Down-regulated & \\
\hline & SERP2283-phosphonate-transport_import & Up-regulated & \\
\hline & SERP2289-MultiDrug-transport_efflux & Up-regulated & \\
\hline
\end{tabular}

a Locus tags are given first (SERP numbers), followed by abbreviated biochemical name and then KEGG reaction numbers (always starting with - m:R...). The effects on S. aureus USA300 were modeled (Table S20 in Additional file 1), are similar overall, and were validated by metabolite measurements. ${ }^{\text {b Down-regulated }}$ means that gene expression was halved (or more then halved); up-regulated means that gene expression was doubled (or more than doubled). Specific values are given in Tables S5 and S6 in Additional file 1. All the enzymes with key changes in expression are part of the complete simulated metabolic model. ${ }^{\mathrm{C}}$ The phenotypes are combination effects of the complete networks, not of single modes (see also Figure S2 in Additional file 1).

tshould neither accumulate nor be lost over time. This condition permits calculation of all enzyme combinations that balance their metabolites inside the network. This yields a list of all metabolic pathways possible for this network [24]. In real situations, such as growth with or without IQ-143, these possible pathways are used quite differently. Next, we calculated the actual flux distribution with a specific program; to do this, direct experimental data are required. The significantly differentially expressed enzymes provide such data and constraints on the flux distribution. This is, of course, a simplification as enzyme activity is modulated allosterically and further factors are involved, such as stability of mRNA and translational regulation. However, the combined errors are strongly reduced by the high number of constraints introduced by the gene expression data. For the complete system of enzymes with significant gene expression changes, the squared deviation between the 


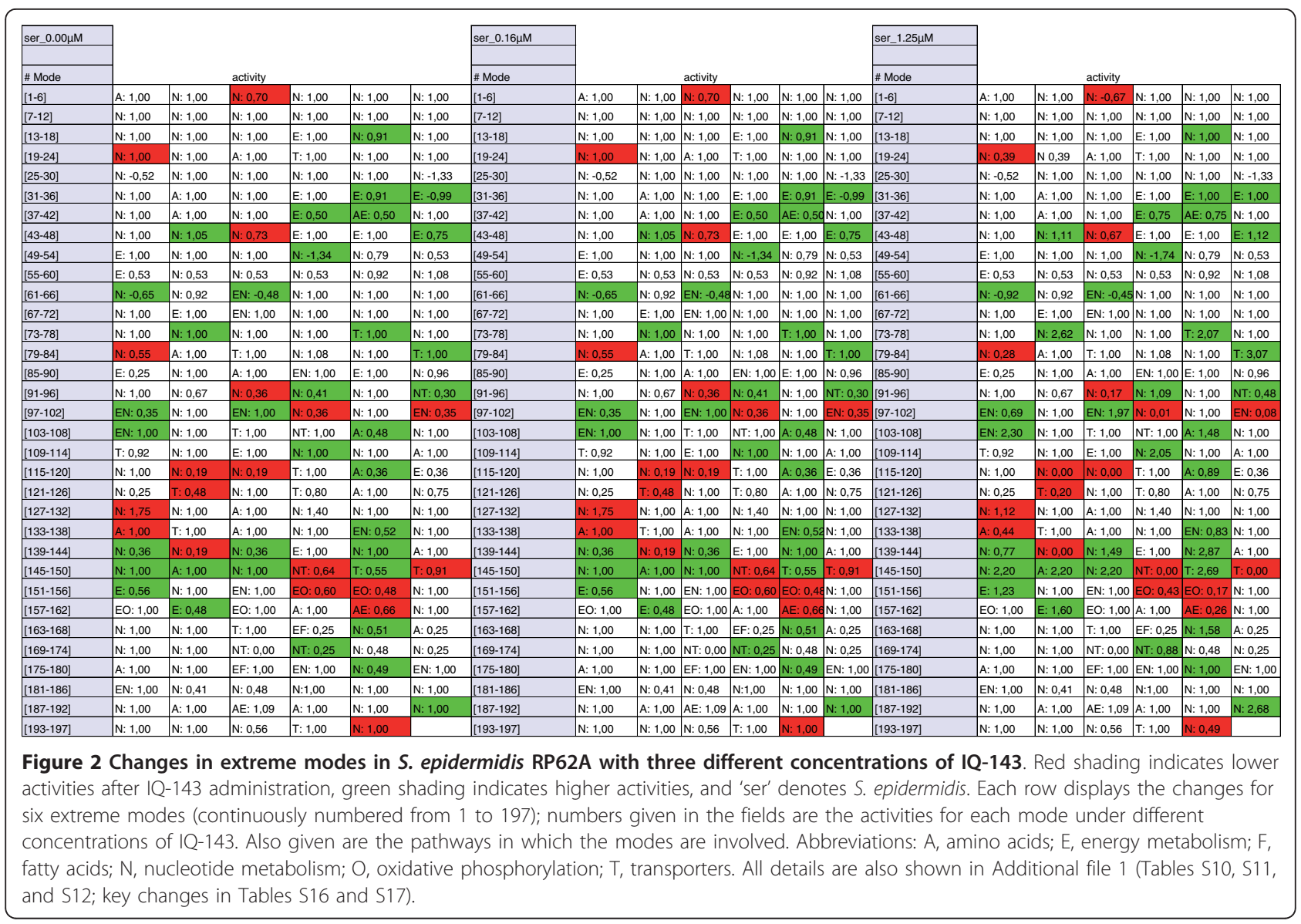

predicted enzyme activity according to the estimated flux distribution and the observed enzyme activity was minimized (least-square minimization combining the genetic algorithm of YANAsquare with a custom written $\mathrm{R}$ routine; see Materials and methods).

From the complete set of flux calculations, several enzyme changes that were not detected by the transcriptome data became apparent (Table 1). Certainly, these are only predictions taking the network effects into account. However, they were subsequently re-checked using metabolite measurements (see below). Numerous repetitions of the transcriptome measurements may also have detected them, as more subtle differences then become significant. On the other hand, the amount of enzyme and activity is likely to be different from subtle transcriptional changes. As an example, combined effects on nucleotide and energy metabolism are described in several extreme pathway modes (Table 1; see, for example, modes 127 and 161 in Tables S7, S8, S9, S10, S11, and S12 in Additional file 1). These flux changes pertain to the enzymes (with EC numbers in parentheses) PNPase (2.4.2.1), glucokinase (2.7.1.2), deoxycytidine kinase (2.7.1.74), DNA-directed RNA polymerase (2.7.7.6), deoxycytidine deaminase (3.5.4.14),
alpha-D-Glucose-1-epimerase (5.1.3.3), and glucose-6phosphate isomerase (5.3.1.9). Furthermore, changes in amino acid metabolism became apparent from the flux changes for modes 35 and 154. Enzymes involved in energy and amino acid metabolism change their activity after administration of IQ-143. This included citric synthase (2.3.3.1), aconitate hydratase (4.2.1.3) and acetyl-CoA synthetase (6.2.1.1) as well as enzymes involved in the conversion of acetyl-CoA to L-valine and the conversion of serine to cysteine.

\section{Annotation of metabolic enzymes and flux balance metabolic model for S. epidermidis and Staphylococcus aureus}

To establish an accurate model of the enzymes involved in the response of staphylococci to IQ-143, we started from the available genome sequences for $S$. epidermidis [Genbank:CP000029, Genbank:CP000028] [17] and S. aureus USA300 [Genbank:CP000730 and Genbank: CP000255] [18] and applied biochemical data on staphylococci according to the KEGG database [25]. We considered all pathways of primary metabolism: amino acid, carbohydrate, lipid, and nucleotide synthesis and degradation, salvage pathways and energy metabolism (Figure 4). 


\begin{tabular}{|c|c|c|c|c|c|c|c|c|c|c|c|c|c|c|c|c|c|c|c|c|}
\hline sau $0.00 \mu \mathrm{M}$ & & & & & & & sau $0.16 \mu \mathrm{M}$ & & & & & & & $\mathrm{u} 1.25 \mu \mathrm{M}$ & & & & & & \\
\hline \# Mode & & & activity & & & & \# Mode & & & etivity & & & & Mode & & & & & & \\
\hline \begin{tabular}{|l}
$1-6]$ \\
\end{tabular} & A: 1,00 & N: 1,00 & $N:-0,65$ & $N: 1,00$ & $N: 1,00$ & N: 1,00 & {$[1-6]$} & A: 1,00 & N: 1,00 & N: - - & N: 1,00 & $N: 1,00$ & N: 1,00 & & A: 1,00 & N: 1,00 & & $\mathrm{~N}: 1,00$ & N: 1,00 & $N: 1,00$ \\
\hline [7-12] & N: 1,00 & N: 1,00 & N: 1,00 & $N: 1,00$ & $\mathrm{~N}: 1,00$ & $\mathrm{~N}: 1,00$ & {$[7-12]$} & N: 1,00 & N: 1,00 & $N: 1,00$ & $N: 1,00$ & N: 1,00 & N: 1,00 & [7-12] & N: 1,00 & N: 1,00 & $N: 1,00$ & & & \\
\hline [13-18] & $\mathrm{N}: 1,00$ & $\mathrm{~N}: 1,00$ & N: 1,00 & $\mathrm{~N}: 1,00$ & E: 0,96 & N: 1,00 & [113-18] & N: 1,00 & N: 1,00 & $N: 1,00$ & $N: 1,00$ & E: 0.98 & N: 1,00 & [13-18] & $N: 1,00$ & N: 1,00 & N: 1,00 & N: 1,00 & E: 0,97 & $N: 1,00$ \\
\hline [19-24] & 1,00 & $\mathrm{~N}: 1,00$ & $\mathrm{~N}: 1,00$ & A: 1,00 & $: 1,00$ & $N: 1,00$ & [199-24] & N: 1,00 & N: 1,00 & N: 1,00 & $A: 1,00$ & T: 1,00 & N: 1,00 & [19-24] & & N: 1,00 & N: 1,00 & A: 1,00 & T: 1,00 & $N: 1,00$ \\
\hline -30] & 0.45 & N: 1,00 & N: 1,00 & 1,00 & 1,00 & N: $: 1,33$ & [25-30] & : $-0,57$ & N: 1,00 & 1,00 & N: 1,00 & N: 1,00 & N: $-1,33$ & 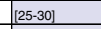 & -0.59 & & N: 1,00 & & N: 1,00 & \\
\hline 36] & : : 1,00 & $\mathrm{N}: 1,00$ & A: 1,00 & 0 & 0,96 & $: 1,00$ & & N: 1,00 & N: 1,00 & 1.00 & N: 1,00 & E: 0,96 & & & v: 1,00 & & A.1 & & & \\
\hline -42] & E: 1,00 & $\mathrm{~N}: 1,00$ & $A: 1,00$ & N: 1,00 & .00 & AE: 1,00 & & $: 1,00$ & N: 1,00 & 1,00 & N: 1,00 & E: 1,00 & 00 & & $E: 1,00$ & & A: 1,00 & & & \\
\hline [43-48] & $\mathrm{N}: 1,00$ & $\mathrm{~N}: 1,00$ & NE: 0,50 & $\mathrm{E}: 1,00$ & $N: 1,00$ & $N: 1,00$ & $\begin{array}{l}\mid[43-48] \\
\end{array}$ & N: 1,00 & N: 1,00 & NE: 0,50 & E: 1,00 & N: 1,00 & N: 1,00 & {$[(43-48]$} & N: 1,00 & N: 1,00 & NE: 0,50 & $\mathrm{E}: 1,00$ & N: 1,00 & $N: 1,00$ \\
\hline $\begin{array}{l}{[49-54]} \\
4\end{array}$ & $N:-0,87$ & $N=0,33$ & $N=0,33$ & $N:-0,33$ & $\mathrm{~N}:-0,33$ & N: $-0,33$ & [499-54] & N: $-0,36$ & $\mathrm{~N}: 0,40$ & N: 0.40 & $N: 0,40$ & N: 0.40 & N: 0.40 & {$[49-54]$} & N: $-0,36$ & N: 0.40 & $\mathrm{~N}: 0,40$ & $N: 0,40$ & N: 0,40 & $N=0,40$ \\
\hline [55-60] & $N: 0,73$ & $\mathrm{~N}: 0,72$ & N: 1,28 & E: $-0,50$ & $\mathrm{~N}: 0,37$ & $\mathrm{~N}: 0,38$ & [55-60] & N: 0,73 & $\mathrm{~N}: 0,72$ & N: 1,21 & E: 0,50 & N: 0,37 & N:0,38 & [55-60] & $\mathrm{N}: 0,95$ & N: 0,92 & N: 1,08 & E: $0 ., 50$ & $\mathrm{~N}:-0,64$ & $\mathrm{~N}: 0,38$ \\
\hline $\begin{array}{l}{[61-66]} \\
\end{array}$ & E: 0,72 & $E: 0,51$ & N: 1,00 & N: 1,00 & N: 1,00 & N: 1,00 & [61-66] & E: 0,88 & $E 0,0,60$ & N: 1,00 & $N: 1,00$ & N: 1,00 & N: 1,00 & {$[\mid 61-66]$} & $\mathrm{E}: 0,92$ & E: $-0,48$ & N: 1,00 & $N: 1,00$ & N: 1,00 & N: 1,00 \\
\hline 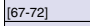 & E: 1,00 & $\mathrm{~N}: 1,00$ & $\mathrm{~N}: 1,00$ & $\mathrm{~N}: 1,00$ & N: 1,00 & N: 1,00 & $\mid[67-72]$ & E: 1,00 & N: 1,00 & $\mathrm{~N}: 1,00$ & N: 1,00 & N: 1,00 & N: 1,00 & |[67-72] & E: 1,00 & N: 1,00 & $N: 1,00$ & $\mathrm{~N}: 1,00$ & $\mathrm{~N}: 1,00$ & $N: 1,00$ \\
\hline \begin{tabular}{|l}
$773-78]$ \\
\end{tabular} & $N: 1,00$ & N: 1,00 & N: 1,00 & T: 1,00 & N: $: 1,00$ & & {$[73-78]$} & $N: 1,00$ & N: 1,00 & IN: 1,00 & T: 1,00 & N: 1,00 & & [73-78] & N:0,39 & N: 1,00 & U: 1,00 & $\mathrm{~T}_{\mathrm{T}: 2,30}$ & N: 1,00 & $\mid \begin{array}{l}\mathrm{N} 0,27 \\
\end{array}$ \\
\hline [799-84] & $A: 1,00$ & T: 1,00 & & $\mathrm{~N}: 1,00$ & & $E: 0.25$ & [79-84] & A: 1,00 & T: 1,00 & & N: 1,00 & $1-$ & E: 0.25 & 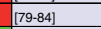 & $A: 1,00$ & T: 1,00 & & N: 1,00 & & $E: 0,22$ \\
\hline $\mid[85-90]$ & N: 1,00 & A: 1,00 & EN: 1,00 & EN 1,00 & N: 1,00 & $N_{N: 0,13}$ & \begin{tabular}{|l}
$855-90]$ \\
\end{tabular} & N: 1,00 & $A: 1,00$ & EN: 1.00 & EN 1,00 & N: 1,00 & N: 1,03 & 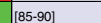 & N: 1,00 & A: 1,000 & EN: 1,00 & EN: 1,00 & N: 1,00 & N: 1,04 \\
\hline 96$]$ & N: 1,00 & \begin{tabular}{|l|l|} 
N. 0,67 \\
\end{tabular} & $\begin{array}{l}\mathrm{N}: 0,38 \\
\end{array}$ & & & NT: 0,31 & & N: 1,00 & N. 0,67 & N: 0,00 & $\mathrm{~N}: 0,23$ & N: 1,00 & $\begin{array}{l}\text { NT: } 0,33 \\
\end{array}$ & & N: 1,00 & & & & & NT: 0,49 \\
\hline-102$]$ & $\mathrm{N}: 0,58$ & NT: 1,00 & $\mathrm{~N}: 1,00$ & $\mathrm{~N}: 0,38$ & EN: 1,00 & 058 & [97-102] & 0,61 & NT: 1,00 & N: 1,00 & $\mathrm{~N}: 2,02$ & EN: 1,00 & & & v: 1,52 & & $\mathrm{~N}: 2,68$ & $\mathrm{~N}: 0,47$ & EN: 1,00 & \\
\hline [103-108] & $\begin{array}{l}\mathrm{N}: 1,00 \\
\end{array}$ & T: 1,00 & NT: 1,00 & A: 1,00 & N: 0,49 & T: 1,00 & {$[1103-108]$} & N: 1,00 & T: 1,00 & NT: 1,00 & A: 1,00 & N: 0,40 & T: 1,00 & [103-108] & $\mathrm{N}: 2,40$ & T: 1,00 & NT: 1,00 & A: 1,00 & $\mathrm{~N}: 1,41$ & $\mathrm{~T}: 1,00$ \\
\hline \begin{tabular}{|l}
$109-114]$ \\
10
\end{tabular} & $\mathrm{~N}: 0,72$ & E: 1,00 & N: 1,00 & $N: 1,00$ & A: 1,00 & N: 1,00 & [109-114] & N: 0,88 & E: 1,00 & N: 1,00 & N: 1,00 & A: 1,00 & N: 1,00 & {$[109-114]$} & N: 0,92 & E: 1,00 & $N: 1,00$ & $\mathrm{~N}: 2,87$ & A: 1,00 & $N=1,00$ \\
\hline \begin{tabular}{|l}
{$[115-120]$} \\
\end{tabular} & N: 1,00 & $N: 0,12$ & T: 0,12 & N: 1,00 & A: 0,38 & EN: 0,38 & {$[115-120]$} & N: 1,00 & $\mathrm{~N}: 0,00$ & T: 2,02 & $N: 1,00$ & $A: 0,00$ & EN: 2002 & {$[115-120]$} & N: 1,00 & $\mathrm{~N}: 0,36$ & T: 0,83 & N: 1,00 & $\mathrm{~A}: 0,54$ & EN: 1,01 \\
\hline$[1121-126]$ & \begin{tabular}{|l}
$\mathrm{N}: 0,25$ \\
\end{tabular} & T: 0,22 & $\mathrm{~N}: 1,00$ & & A: 1,00 & \begin{tabular}{|l}
$\mathrm{N}: 0,75$ \\
\end{tabular} & {$[1121-126]$} & N: 0,25 & T: 1,000 & $\mathrm{~N}: 1,00$ & T: 0.80 & A: 1,00 & N: 0,75 & {$[1121-126]$} & $\mathrm{N}: 0,25$ & T: 1,97 & N: 1,00 & T: 0,80 & A: 1,00 & $\mathrm{~N}: 0,72$ \\
\hline 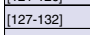 & N: 1,50 & $\mathrm{N}: 1,00$ & A: 1,00 & N: 0,60 & $\mathrm{~N}: 1,00$ & $N: 1,00$ & {$[1127-132]$} & N: 1,50 & N: 1,00 & $A: 1,00$ & N: 1,40 & $N: 1,00$ & N: 1,00 & {$[(127-132]$} & $\begin{array}{ll}N \\
N: 1,50\end{array}$ & N: 1,00 & A: 1,00 & & $\mathrm{~N}: 1,00$ & $N: 1,00$ \\
\hline \begin{tabular}{|l}
$1133-1388$ \\
\end{tabular} & $\mathrm{~N}: 1,00$ & A: 1,00 & T: 1,00 & A: 1,00 & & EN: 1,00 & {$[1(133-138]$} & & $A: 1,00$ & T: 1,00 & A: 1,00 & $\mathrm{~N}: 0,57$ & EN: 1,00 & {$[133-138]$} & & $A: 1,00$ & $\mathrm{~T}: 1,00$ & A: 1,00 & N: 0,85 & EN: 1,00 \\
\hline 9-144] & $\mathrm{N}: 0,38$ & $\mathrm{~N}: 0,12$ & $\mathrm{~N}: 0,38$ & 100 & $E: 1,00$ & $N: 1,00$ & {$[133$.} & $N: 0,00$ & $\mathrm{~N}: 0,000$ & $N: 0,00$ & N: 1,00 & E: 1,00 & $N: 1,00$ & & $\mathrm{~N}: 0,59$ & $\mathrm{~N}: 0,96$ & $\mathrm{~N}: 1,14$ & & $\mathrm{E}: 2,20$ & $N: 1,00$ \\
\hline $5-150]$ & $A: 1,00$ & $N: 1,00$ & $N=1,00$ & & v: 0,41 & & {$[145-150]$} & 1,00 & N: 1,00 & N: 1,00 & A: 0,57 & & & 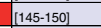 & $A: 2,20$ & & $N: 2$ & & & \\
\hline 1-156] & T: 0,64 & T: 1,00 & E: 1,00 & & EN: 0.45 & EO: 1,00 & {$[1151-156]$} & 0.72 & T: 1,00 & E: 1,00 & $\begin{array}{ll}N: U \\
\end{array}$ & EN: 0,43 & EO: 1,00 & {$[151-15 \mathrm{E}$} & T:1,55 & $\mathrm{T}: 1,00$ & $\mathrm{E}: 1,00$ & $\mathrm{~N}: 0.00$ & NA: 0,15 & EO: 1,00 \\
\hline 77-162] & EO: 1,00 & $\mathrm{~N}: 0,22$ & EO: 1,00 & .00 & EO: 0.27 & A: 1,00 & {$[157-162]$} & EO: 1,00 & $N: 1,00$ & EO: 1,00 & E: 1,00 & EO: 0,21 & A: 1,00 & $1577-162]$ & EO: 1,00 & N:2,06 & EO: 1,00 & E: 1,00 & EO: 0.05 & A: 1,00 \\
\hline$[163-168]$ & AE: 1,00 & N: 1,00 & $\mathrm{N}: 1,00$ & $\mathrm{~N}: 0,25$ & $\mathrm{~T}: 1,25$ & EF: 1,00 & [163-168] & AE: 1,00 & $N: 1,00$ & N: 1,00 & $\mathrm{~N}: 0,25$ & T: 1,25 & EFF: 1,00 & {$[\mid[163-168]$} & AE: 1,00 & N: 1,00 & $\mathrm{~N}: 1,00$ & $\mathrm{~N}: 0,25$ & $\mathrm{~T}: 1,25$ & EF: 1,00 \\
\hline $\mid(169-174]$ & $\mathrm{N}: 0,25$ & $A: 1,00$ & $\mathrm{~N}: 1,00$ & N: 1,00 & $\mathrm{~N}: 0,50$ & NT: 0.49 & {$[(169-174]$} & N: 0,25 & A: 1,00 & N: 1,00 & $N: 1,00$ & $N: 0,50$ & NT: : 0,49 & {$[169-174]$} & $\mathrm{N}: 0,25$ & A: 1,00 & $N: 1,00$ & N: 1,00 & $\mathrm{~N}: 0,50$ & NT: 0,49 \\
\hline$[1775-180]$ & \begin{tabular}{|l|l} 
NT: 0,25 \\
\end{tabular} & N: 1,00 & N: 1,00 & A: 1,00 & $\mathrm{~N}: 1,00$ & EF: 0,75 & (1775-1800) & NT: 0,25 & N: 1,00 & $N: 1,00$ & A: 1,00 & $N: 1,00$ & EF: 0.90 & $1175-1$ & NT: 0,25 & N: 1,00 & N: 1,00 & A: 1,00 & N: 1,00 & EF: 0,80 \\
\hline$[181-186]$ & EN: 1,00 & $\mathrm{~N}: 1,00$ & NT: 0,15 & $\mathrm{~N}: 0,27$ & $\mathrm{~N}: 1,00$ & N: 1,00 & {$[181-186]$} & EN: 1,00 & $\mathrm{~N}: 1,00$ & NT: 0,23 & & $N: 1,00$ & N: 1,00 & $(181-1)$ & EN: 1,00 & $\mathrm{~N}: 1,00$ & NT: 0.53 & $\mathrm{~N}: 0,05$ & $N: 1,00$ & $N: 1,00$ \\
\hline$[187-192]$ & $\mathrm{N}: 1,00$ & $\mathrm{~N}: 1,00$ & $A: 1,00$ & AE: 1,04 & A: 1,00 & $\begin{array}{l}N: 1,00 \\
N\end{array}$ & {$[\mid[187-192]$} & N: 1,00 & N: 1,00 & $A: 1,00$ & AE: 1,04 & A: 1,00 & $N: 1,00$ & (187-1 & N: 1,00 & $N: 1$, & A: 1,00 & AE: 1,04 & A: 1,00 & $N: 1,00$ \\
\hline 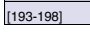 & $N: 1,00$ & N: 1,00 & $N: 1,00$ & - & T: 1,00 & N: 1,00 & [193-198] & 1,00 & N: 1,00 & $\mid N: 1,00$ & & T: 1,00 & N: 1,00 & {$[(193-198]$} & & N: 1,00 & $\mathrm{~N}: 1,00$ & $\mathrm{~N}: 0,52$ & T: 1,00 & $\begin{array}{l}N: 2,82 \\
\end{array}$ \\
\hline \multicolumn{21}{|c|}{$\begin{array}{l}\text { Figure } 3 \text { Changes in extreme modes in S. aureus USA } 300 \text { with three different concentrations of IQ-143. Red shading indicates lower } \\
\text { activities after IQ-143 administration, green shading indicates higher activities, and 'sau' denotes S. aureus. Each row displays six extreme modes } \\
\text { (continuously numbered from } 1 \text { to 198); numbers given in the fields are the activities for each mode under different concentrations of IQ-143. } \\
\text { Also given are the pathways in which the modes are involved. Abbreviations: A, amino acids; E, energy metabolism; F, fatty acids; N, nucleotide } \\
\text { metabolism; O, oxidative phosphorylation; T, transporters. All details are also shown in Additional file } 1 \text { (Tables S7, S8, and S9; key changes in } \\
\text { Tables S18 and S19). }\end{array}$} \\
\hline
\end{tabular}

We established models for both S. aureus and S. epidermidis; S. aureus is well known as a dangerous pathogen, but infections by $S$. epidermidis (normally a commensal of the skin) are increasingly common due to the biofilm-forming capacity of this pathogen and its development of resistance to a broad spectrum of antibacterial agents [26].

We performed sequence and domain analyses [19] to identify several enzymes that had escaped previous annotation efforts, such as nucleoside-triphosphate diphosphatase and thymidine phosphorylase in both strains (Table S1 in Additional file 1), and verified their occurrence in the cDNA of total RNA from S. epidermidis by PCR (Figure 6S in Additional file 1). The genome sequences were meticulously analyzed by sequence analysis. In addition, we searched in available data banks for enzyme repertoires of both organisms, and different enzyme reading frames were validated by PCR on the mRNAs from these organisms. Any verified discrepancies by these different checks were next incorporated into the generated metabolic models so that pathways with different enzyme repertoires are different in the two models. For instance, S. aureus USA300 has only one AMP-pyrophosphorylase and one GMP-pyrophosphorylase, whereas S. epidermidis RP62A has two of each. On the other hand S. aureus USA300 has a XMPligase, whereas S. epidermidis RP62A does not.

Our complete models (reactions in Tables S2 and S3 in Additional file 1) of metabolism in staphylococci systematically included all pathways for which gene expression data pointed to major changes (Tables 1 and 2) in individual enzyme expression after applying different concentrations of IQ-143. Furthermore, the metabolic capabilities of these models were calculated applying YANA [21].

\section{Changes in reactions and enzyme activity of $S$. aureus} and S. epidermidis after administration of IQ-143

Using the above experimental data and the two strainspecific metabolic models, we compared standard growth to the reduced growth after administration of IQ-143 (see Materials and methods). Several speciesspecific differences with regards to reactions were observed after administration of IQ-143 in S. aureus compared to $S$. epidermidis. These are summarized in Figures 2 and 3 (details in Tables S7, S8, S9, S10, S11 and S12). Thus, some modes are only up-regulated (for example, modes 49 and 54 for pyrimidine metabolism in S. aureus, but not in S. epidermidis) or only down-regulated (for example, modes 44 and 193 for pyrimidine 


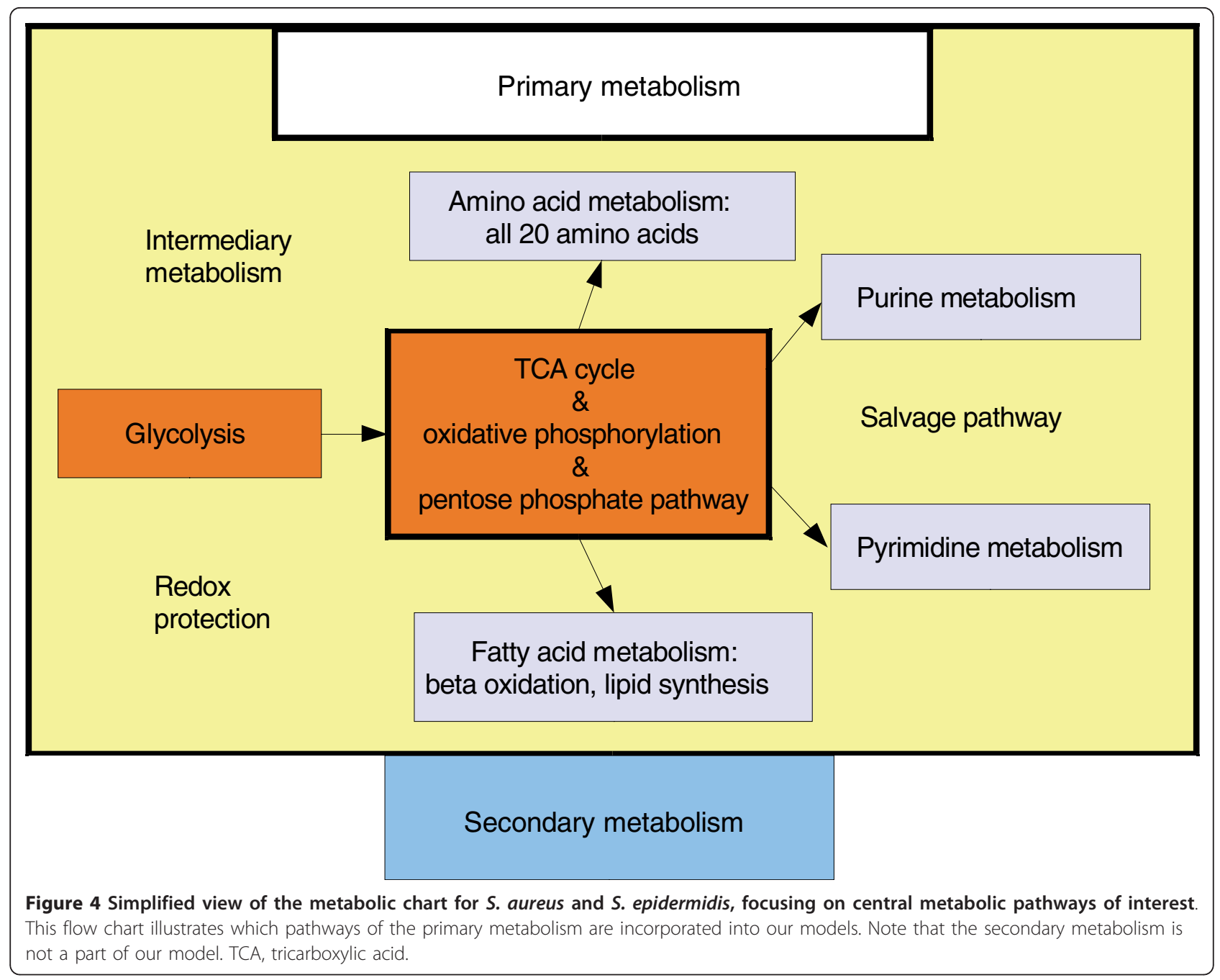

metabolism in S. epidermidis, but not changed in S. aureus). Some metabolic modes are oppositely regulated in the two strains. For example, mode 122 (involving several transporter proteins for choline, carnithin and betaine) is up-regulated in $S$. aureus but down-regulated in S. epidermidis. Nevertheless, most of the calculated metabolic fluxes were similar to those obtained for $S$. epidermidis applying the gene expression data as constraints (Tables S18 and S19 in Additional file 1 detail further changes). Several enzyme changes in S. epidermidis and $S$. aureus that were not observable from the transcriptome data became apparent only after applying the metabolic modeling (Figures 5 and 6; bars with dotted outlines indicate changes already indicated by the gene expression data). For example, DNA-directed RNA-polymerases do not change significantly in their respective gene expression, but have clearly different activities under the influence of different concentrations of IQ-143.
The combination of all data with the strain-specific metabolic models showed an effect of IQ-143 on energy metabolism, DNA and RNA elongation as well as bacterial growth for both species (Figure S2 in Additional file 1).

The activity increase in extreme pathway mode 61 (Table S18 in Additional file 1) for the enzymes glucose-6-phosphate isomerase (5.3.1.9), alpha/beta D-glucokinase (2.7.1.1), adenylate kinase (2.7.4.10), and Dglucose-1-epimerase (5.1.3.3) is only visible in $S$. aureus.

Pathway effects of different concentrations of IQ-143 in S. epidermidis and S. aureus

Metabolic modeling took advantage of enzyme gene expression changes from the array data by using these data as constraints for the metabolic flux calculations. This allowed us to estimate the effects of different degrees of environmental change after the administration of different concentrations of IQ-143 on not only 


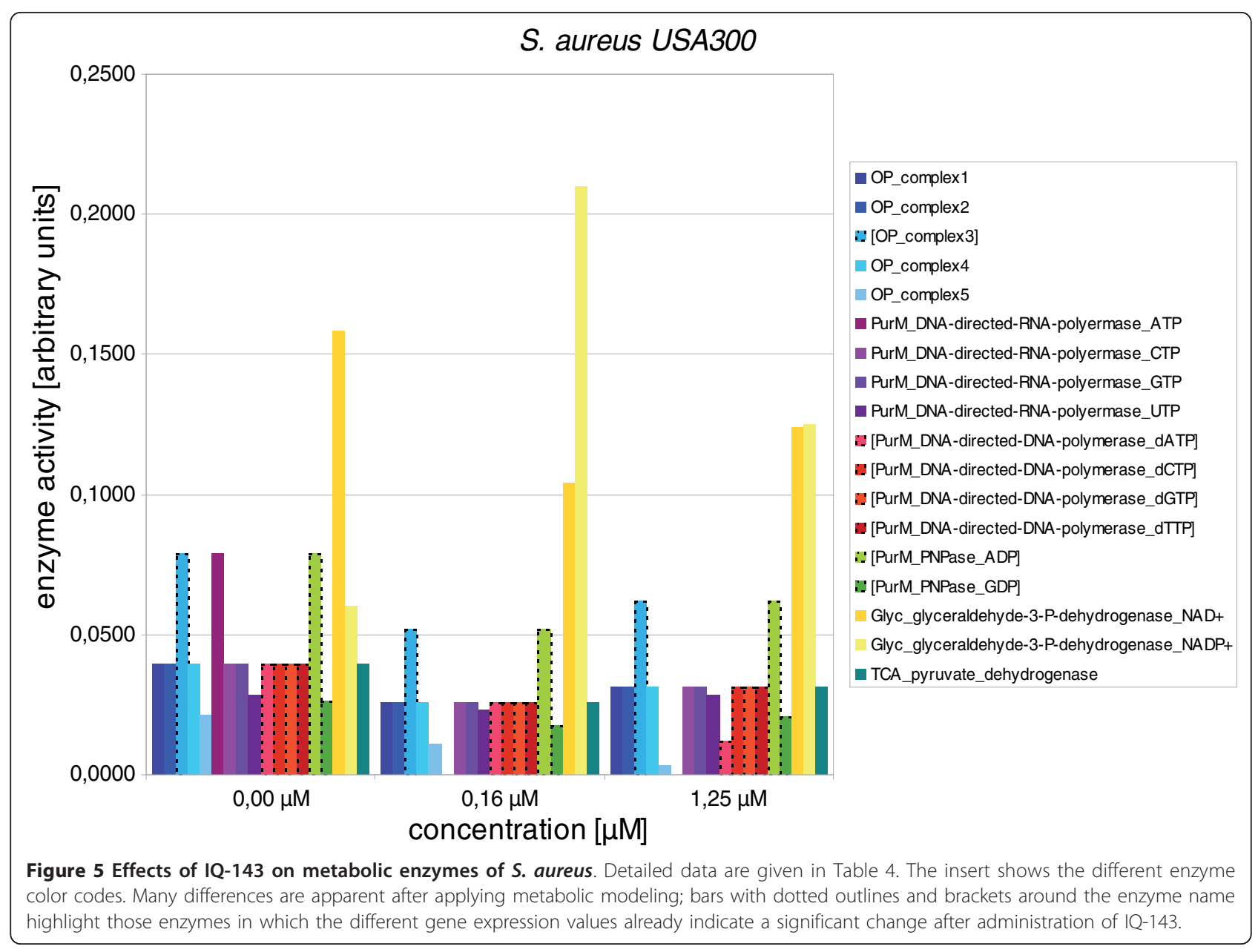

the metabolism of individual enzymes but also on entire pathways. Using the gene expression changes as constraints in a metabolite flux model to estimate the changes in individual metabolic fluxes after administration of IQ-143, YANAsquare allowed us to calculate the resulting change for each flux and all enzymes in the network [22]. The constraints on the gene expression of several enzymes are of course only a simple first-order estimate of enzyme activity. However, it turned out that the given number (31) of constraints in the model, which were estimated according to significant gene expression changes as well as the tight connections between different pathways in the metabolic network, are sufficient for optimized flux estimates. In particular, the estimated fluxes are in accordance with the measured experimental metabolite concentrations and their changes (see below).

One could expect a general stress response from the administered IQ-143. In fact, we identified stress response mechanisms of $S$. epidermidis RP62A against IQ-143 (Table 3). However, we found significant up-regulation of stress response genes only for two genes after looking at all genes that were up-regulated: SERP2244 and SERP1998. SERP2244 encodes a bacterial capsule synthesis protein (PGA_cap), which may help the bacteria to resist high salt concentrations and may also be involved in virulence $[27,28]$. SERP1998 is a putative activator of the Hsp90 ATPase homolog 1-like protein. Up-regulation of Hsp90 results in higher survival under conditions of increased stress [29,30]. However, genes belonging to the sigmaB-dependent stress regulon are not affected by IQ-143. Furthermore, the transcriptome data show that several ABC transporters are up-regulated by IQ-143. ABC transporters are often involved in multi-drug resistance as they function as trans-membrane efflux pumps for active transport of several xenobiotics, including anti-infective substances [31]. In staphylococci, several ABC transporters, such as MsrA (conferring resistance to macrolides, lincosamides, streptogramins), TetK (conferring resistance to tetracycline), NorA (conferring resistance to fluoroquinolones), VgaAB (conferring resistance to streptogramins), and FusB (conferring resistance to fusidic acid), have been shown to be involved in antibiotic resistance [32]. 


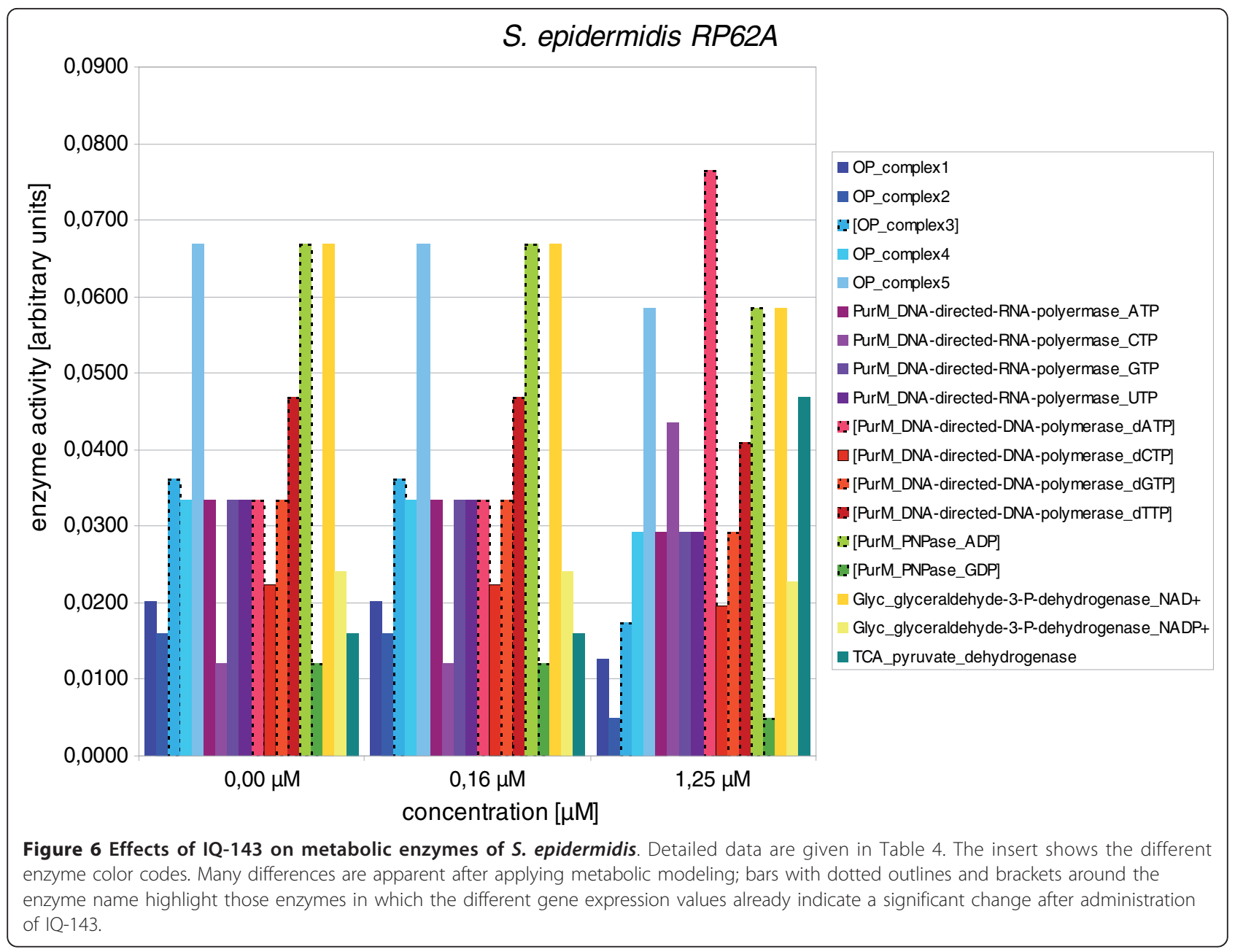

However, the $\mathrm{ABC}$ transporters deregulated by IQ-143 in this study have not been documented to be involved in resistance to xenobiotics yet. Further studies are needed to clarify the exact role of these transporters in resistance.

Gene expression differences (Table 1) and detailed modeling of metabolism suggest that key changes are not located in just one particular subnetwork: DNA and RNA elongation is up-regulated (two-fold), and oxidative phosphorylation complex 3 is up-regulated (eightfold). By contrast, glycolysis as well as lactate dehydrogenase (1.1.1.27) are down-regulated (by 50\%).
In particular, enzymes of the oxidative phosphorylation and purine pathways are primarily affected upon application of IQ-143 (Table 4). In purine metabolism, the enzymes utilizing inosine monophosphate (IMP) are impeded as well as complex 1 and 3 (Figures 5 and 6) of oxidative phosphorylation. Also, there is a drop in activity of some DNA and RNA polymerases. Figures 2 and 3 provide detailed information on the complete metabolic effects calculated from the data using YANAsquare [22].

The changes in complexes 1 and 3 are of particular interest. These significant changes in activity suggest

Table 3 Identification of stress response mechanisms in S. epidermidis RP62A ${ }^{1}$

\begin{tabular}{|c|c|c|c|c|c|c|}
\hline \multirow[b]{2}{*}{ Query } & \multicolumn{6}{|c|}{ Hit } \\
\hline & Family & Description & Entry type & Clan & Bit score & E-value \\
\hline SERP2244 & PGA_cap & Bacterial capsule synthesis protein PGA_cap & Domain & CL0163 & 233.2 & $2.3 e-69$ \\
\hline SERP1998 & AHSA1 & Activator of Hsp90 ATPase homolog 1-like protein & Family & CL0209 & 67.8 & $6.9 e-19$ \\
\hline
\end{tabular}

This table provides BLAST [48] results of the two putative stress response mechanisms of S. epidermidis RP62A we detected by iterative sequence search. PGA_cap encodes a poly-gamma-glutamate capsule, which could improve the survivability under salt stress. AHSA1 encodes an activator of the Hsp90 ATPase homolog 1-like protein, which results in an increase of efficiency of the Hsp90 function and thus leads to higher survivability under stress conditions. 
Table 4 Effects of IQ-143 on diverse enzymes of oxidative phosphorylation and energy and nucleotide metabolism of S. aureus USA300 and S. epidermidis RP62A

\begin{tabular}{|c|c|c|c|}
\hline \multirow[b]{2}{*}{ Enzyme $^{a}$} & \multicolumn{3}{|c|}{ Concentration of IQ-143 $(\mu \mathrm{M})^{\mathrm{b}}$} \\
\hline & 0.00 & 0.16 & 1.25 \\
\hline \multicolumn{4}{|l|}{ S. aureus USA300 } \\
\hline OP_complex1 & 0.0396 & 0.0260 & 0.0310 \\
\hline OP_complex2 & 0.0396 & 0.0260 & 0.0310 \\
\hline [OP_complex3] & 0.0791 & 0.0520 & 0.0619 \\
\hline OP_complex4 & 0.0396 & 0.0260 & 0.0310 \\
\hline OP_complex5 & 0.0214 & 0.0109 & 0.0031 \\
\hline PurM_DNA-directed-RNA-polymerase_ATP & 0.0791 & 0.0000 & 0.0000 \\
\hline PurM_DNA-directed-RNA-polymerase_CTP & 0.0396 & 0.0260 & 0.0310 \\
\hline PurM_DNA-directed-RNA-polymerase_GTP & 0.0396 & 0.0260 & 0.0310 \\
\hline PurM_DNA-directed-RNA-polymerase_UTP & 0.0285 & 0.0229 & 0.0285 \\
\hline [SERP0831-PurM_DNA-directed-DNA-polymerase_dATP] & 0.0396 & 0.0260 & 0.0121 \\
\hline [SERP0831-PurM_DNA-directed-DNA-polymerase_dCTP] & 0.0396 & 0.0260 & 0.0310 \\
\hline [SERP0831-PurM_DNA-directed-DNA-polymerase_dGTP] & 0.0396 & 0.0260 & 0.0310 \\
\hline [SERP0831-PurM_DNA-directed-DNA-polymerase_dTTP] & 0.0396 & 0.0260 & 0.0310 \\
\hline [SERP0841-PurM_PNPase_ADP] & 0.0791 & 0.0520 & 0.0619 \\
\hline [SERP0841-PurM_PNPase_GDP] & 0.0265 & 0.0174 & 0.0207 \\
\hline Glyc_glyceraldehyde-3-P-dehydrogenase_NAD+ & 0.1582 & 0.1040 & 0.1238 \\
\hline Glyc_glyceraldehyde-3-P-dehydrogenase_NADP+ & 0.0601 & 0.2102 & 0.1251 \\
\hline TCA_pyruvate_dehydrogenase & 0.0396 & 0.0260 & 0.0310 \\
\hline \multicolumn{4}{|l|}{ S. epidermidis RP62A } \\
\hline OP_complex1 & 0.0201 & 0.0201 & 0.0126 \\
\hline OP_complex2 & 0.0161 & 0.0161 & 0.0050 \\
\hline [OP_complex3] & 0.0361 & 0.0361 & 0.0175 \\
\hline OP_complex4 & 0.0334 & 0.0334 & 0.0292 \\
\hline OP_complex5 & 0.0669 & 0.0669 & 0.0585 \\
\hline PurM_DNA-directed-RNA-polymerase_CTP & 0.0334 & 0.0334 & 0.0292 \\
\hline PurM_DNA-directed-RNA-polymerase_GTP & 0.0120 & 0.0120 & 0.0436 \\
\hline PurM_DNA-directed-RNA-polymerase_UTP & 0.0334 & 0.0334 & 0.0292 \\
\hline PurM_DNA-directed-RNA-polymerase_ATP & 0.0334 & 0.0334 & 0.0292 \\
\hline [SERP0831-PurM_DNA-directed-DNA-polymerase_dATP] & 0.0334 & 0.0334 & 0.0766 \\
\hline [SERP0831-PurM_DNA-directed-DNA-polymerase_dCTP] & 0.0224 & 0.0224 & 0.0196 \\
\hline [SERP0831-PurM_DNA-directed-DNA-polymerase_dGTP] & 0.0334 & 0.0334 & 0.0292 \\
\hline [SERP0831-PurM_DNA-directed-DNA-polymerase_dTTP] & 0.0468 & 0.0468 & 0.0409 \\
\hline [SERP0841-PurM_PNPase_ADP] & 0.0669 & 0.0669 & 0.0585 \\
\hline [SERP0841-PurM_PNPase_GDP] & 0.0120 & 0.0120 & 0.0050 \\
\hline Glyc_glyceraldehyde-3-P-dehydrogenase_NAD+ & 0.0669 & 0.0669 & 0.0585 \\
\hline Glyc_glyceraldehyde-3-P-dehydrogenase_NADP+ & 0.0241 & 0.0241 & 0.0228 \\
\hline TCA_pyruvate_dehydrogenase & 0.0161 & 0.0161 & 0.0468 \\
\hline
\end{tabular}

This table lists the effects of three different concentrations of IQ-143 on the activity of diverse enzymes of the described pathways and reactions in S. aureus USA300 and S. epidermidis RP62A. a Enzymes in brackets were also detected by their gene expression change in S. epidermidis RP62A. ${ }^{b}$ Concentrations tested were no IQ-143, $0.16 \mu \mathrm{M}$ IQ-143 and 1.25 $\mu \mathrm{M}$ IQ-143. PurM, purine metabolism.

two possible modes of action for IQ-143: either NADH is not produced in a sufficient quantity any more due to various effects of IQ-143, or the compound competes in a direct way with NADH in certain enzymes. Regarding the first possibility, IMP-utilizing enzymes are also affected by IQ-143 if administered at a concentration of at least 1.25 $\mu \mathrm{M}$ (Tables S20 and S21 in Additional file
1). In particular, S. epidermidis and S. aureus have to use enzymes located in the glycolysis and pentose phosphate pathway to produce enough ribosylamine-5-phosphate, the initial step in IMP production. Some of these reactions use $\mathrm{NAD}^{+}$and produce NADH as a co-substrate (for example, glyceraldehyde-3-phosphate dehydrogenase in lower glycolysis). $\mathrm{NAD}^{+}$-utilizing enzymes 
Table 5 Concentrations of CMP, AMP, GMP, XMP, and TMP

\begin{tabular}{lcccccccc}
\hline & \multicolumn{2}{c}{ Control } & \multicolumn{3}{c}{$\mathbf{0 . 1 6} \boldsymbol{\mu M}$ IQ-143 } & \multicolumn{2}{c}{$\mathbf{1 . 2 5} \boldsymbol{\mu M}$ IQ-143 } \\
\cline { 2 - 8 } & Mean $(\boldsymbol{\mu g} / \mathbf{m l})$ & SD & Mean $(\boldsymbol{\mu g} / \mathbf{m l})$ & SD & \% of control & Mean $(\boldsymbol{\mu g} / \mathbf{m l})$ & SD & \% of control \\
\hline CMP & 21.03 & 0.96 & $24.41^{*}$ & 0.24 & 116.07 & $3.86^{* *}$ & 0.19 & 18.35 \\
TMP & 1.61 & 0.12 & 1.67 & 0.11 & 103.76 & $8.81^{*}$ & 0.24 & 547.20 \\
AMP & 0.42 & 0.06 & $0.12^{*}$ & 0.02 & 28.57 & $20.37^{* *}$ & 0.80 & 4850.00 \\
GMP & 1.51 & 0.05 & $1.44^{* *}$ & 0.05 & 95.36 & $3.66^{*}$ & 0.21 & 242.38 \\
XMP & 2.62 & 0.20 & $3.96^{* *}$ & 0.16 & 151.15 & $3.44^{* *}$ & 0.11 & 131.30 \\
\hline
\end{tabular}

Direct measurement of CMP, AMP, GMP, XMP, and TMP concentrations in S. aureus (in $\mu \mathrm{g} / \mathrm{ml}$ and in percentage of control value depending on the applied IQ143 concentration). Statistically significant differences are indicated $\left({ }^{*} P<0.05,{ }^{* *} P<0.01\right)$. SD, standard deviation.

are significantly down-regulated by 10 to $15 \%$ (see Tables S20 and S21 in Additional file 1). One scenario of drug action for IQ-143 predicts that if IMP synthesis is impaired (at least 1.25 $\mathrm{M}$ IQ-143), there is less $\mathrm{NADH}$ available. This, in turn, is responsible for the drop in efficiency of complex 1 of oxidative phosphorylation, which thus also impedes complex 3. This theory is supported by the results shown in Table 5 for higher concentrations of IQ-143, where the changes in nucleotide concentrations after application of IQ-143 to S. aureus are shown. Whereas $0.16 \mu \mathrm{M}$ IQ-143 reduced AMP concentration by approximately 70\% (control, $0.42 \mu \mathrm{g} /$ $\mathrm{ml} ; 0.16 \mu \mathrm{M}$ IQ-143, $0.12 \mu \mathrm{g} / \mathrm{ml}$ ), an almost 50-fold increase in AMP concentration was observed with 1.25 $\mu$ M IQ-143 (Table 6). Such an accumulation of AMP is most likely the consequence of decreased production of ATP by oxidative phosphorylation.

A second potential mode of action for IQ-143 would be that it directly acts as a NADH competitor and impairs the production of $\mathrm{NAD}^{+}$. This again leads to the effects described above, although this time the reduced pool of $\mathrm{NAD}^{+}$and not the inhibition of NADH-producing enzymes is responsible for the calculated effects.

\section{Metabolite measurements in S. aureus}

To better examine these possibilities, we conducted direct metabolite measurements by HPLC-UV and quantitatively measured the metabolic changes due to the administered xenobiotic IQ-143 (that is, metabonomics as defined by Nicholson [33]). In contrast to the modeled metabolic fluxes (see the previous section of Results), these are direct measurements and are used to validate and re-test the predictions regarding the resulting metabolite levels.

The data show a complex pattern of cell alterations upon administration of IQ-143: the nicotinamide-adenine dinucleotides $\mathrm{NAD}^{+}, \mathrm{NADH}$ and NADP show substantial decreases of between 10 and $30 \%$ and between 30 and $50 \%$ dependent on the applied concentration of the inhibitor $(0.16 \mu \mathrm{M}$ and1.25 $\mu \mathrm{M}$ IQ-143, respectively; Figure 7). In turn, the reduced phosphate form NADPH undergoes a two-fold increase (with $1.25 \mu \mathrm{M}$ IQ-143). Table 6 gives an overview of the metabolite measurements and shows significant differences in these with various concentrations of applied IQ-143.

Additionally, strong changes occurred in the metabolite profile of purine metabolism. Pathway modeling of these data suggests down-regulation of purine metabolism as well as further effects also on the pyrimidine metabolism. Thymidine-5'-monophosphate (TMP) and cytidine-5'monophosphate (CMP) show statistically significant changes: the concentration of TMP increased five-fold upon treatment with $1.25 \mu \mathrm{M}$ IQ-143, and CMP production was reduced to $20 \%$ compared to the control. The lower inhibitor concentration $(0.16 \mu \mathrm{M})$ resulted in only a slight increase in CMP. The concentrations of all nucleotides increase at high concentrations of IQ-143 (Figure 8, Table 5). By contrast, the changes with low IQ143 concentrations are more heterogeneous.

\section{Metabolic effects of different concentrations of IQ-143 on human cells}

The combined effects of IQ-143 are bacteriostatic and, at higher concentrations, bactericidal on S. aureus and

Table 6 Concentration of NAD, NADH, NADP, and NADPH

\begin{tabular}{|c|c|c|c|c|c|c|c|c|}
\hline & \multicolumn{2}{|c|}{ Control } & \multicolumn{3}{|c|}{$0.16 \mu \mathrm{M}$ IQ-143 } & \multicolumn{3}{|c|}{$1.25 \mu \mathrm{M}$ IQ-143 } \\
\hline & Mean $(\mu \mathrm{g} / \mathrm{ml})$ & SD & Mean $(\mu \mathrm{g} / \mathrm{ml})$ & SD & $\%$ of control & Mean $(\mu \mathrm{g} / \mathrm{ml})$ & SD & $\%$ of control \\
\hline$\overline{N A D}$ & 42.19 & 2.44 & $35.68^{* *}$ & 0.92 & 84.57 & $27.89^{* *}$ & 0.95 & 66.11 \\
\hline $\mathrm{NADH}$ & 3.71 & 0.31 & $2.63^{* *}$ & 0.28 & 70.89 & $1.95^{* *}$ & 0.21 & 52.56 \\
\hline NADP & 3.47 & 0.06 & $3.24^{* *}$ & 0.05 & 93.37 & $2.42^{* *}$ & 0.05 & 69.74 \\
\hline NADPH & 2.87 & 0.12 & $2.25^{* *}$ & 0.02 & 78.40 & $5.56^{* *}$ & 0.22 & 193.73 \\
\hline
\end{tabular}

Direct measurement of NAD, NADH, NADP, and NADPH concentrations in S. aureus (in $\mu \mathrm{g} / \mathrm{ml}$ and percentage of control value depending on the applied IQ-143 concentration). Statistically significant differences are indicated $\left.{ }^{*} P<0.05,{ }^{*} P<0.01\right)$. SD, standard deviation. 


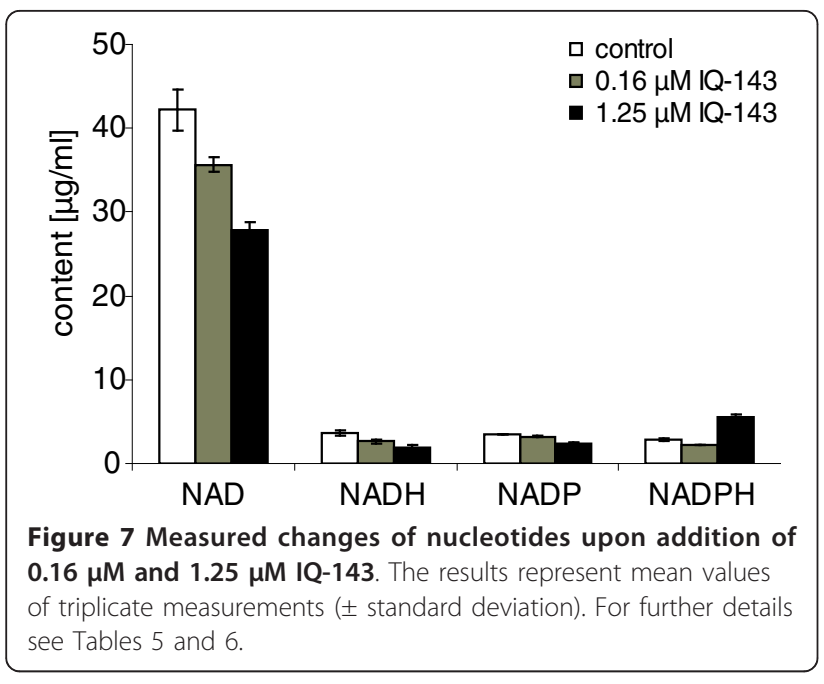

S. epidermidis. This supports the use of IQ-143 as a potential antibiotic lead compound for the development of a novel class of antibiotics against staphylococcal infections. However, for clinical application, the therapeutic width and toxic effects in human cells have to be considered. As a start in this direction, we combined direct measurements in cultured human cells with in vitro measurements of enzyme activity of the CYP oxidase system involved in xenobiotic detoxification (Table 7 ). The direct measurements in cultured human cells revealed $\mathrm{IC}_{50}$ values that indicate that IQ-143 has toxic effects (see Materials and methods) on human kidney 293T human embryonal cells and macrophage (J774.1) cells at a dose of approximately $40 \mu \mathrm{M}$.

With regard to the in vitro measurements, we experimentally investigated the effects of IQ-143 on the six main human liver drug metabolizing CYP enzymes, 1A2, 2C8/9/19, 2D6 and 3A4, using a previously

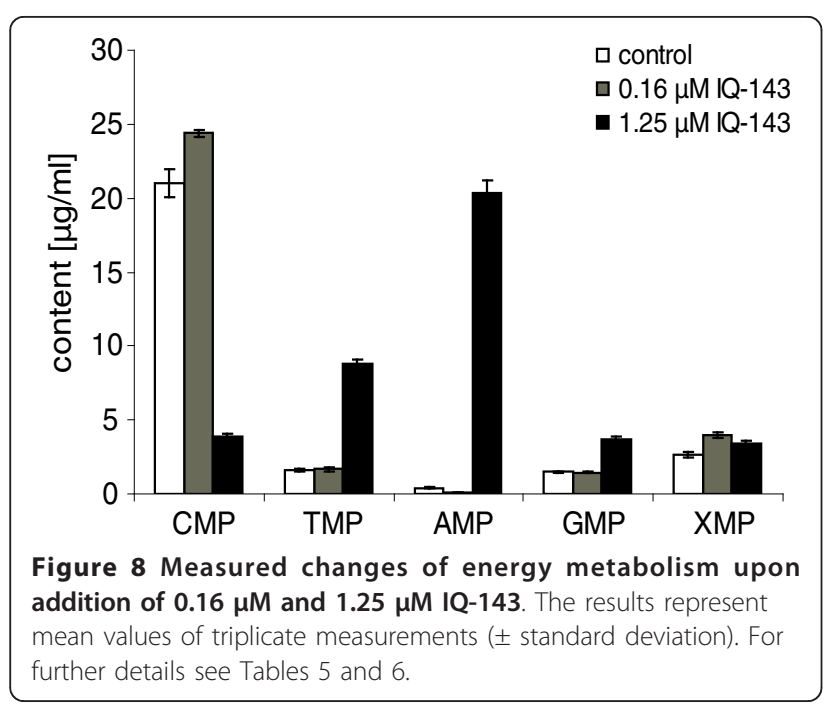

Table 7 Effects on human cytochrome P450 function in vitro

\begin{tabular}{lccc}
\hline Cytochrome enzyme & \multicolumn{3}{c}{ Percentage of control activity } \\
\cline { 2 - 4 } & $\mathbf{1} \boldsymbol{\mu M}$ IQ-143 & $\mathbf{1 0} \boldsymbol{\mu M}$ IQ-143 & $\mathbf{1 0 0} \boldsymbol{\mu M}$ IQ-143 \\
\hline 1A2 & 106.9 & 127.3 & 126.2 \\
2C8 & 142.8 & 144.0 & 146.0 \\
2C9 & 122.7 & 130.0 & 142.0 \\
2C19 & 102.2 & 101.8 & 90.1 \\
2D6 & 99.1 & 100.9 & 58.7 \\
3A4 & 98.6 & 95.3 & 6.6 \\
\hline
\end{tabular}

CYP enzymes derived from baculovirus-infected insect cells were incubated with the corresponding substrates and IQ-143 at concentrations of $1 \mu \mathrm{M}, 10$ $\mu \mathrm{M}$, and $100 \mu \mathrm{M}$ as described by Unger and Frank [34]. As shown here (and in Figure S3), only very high doses of IQ-143 reduced the activity of the CYP isoenzymes 2C19,2D6, and 3A4. At concentrations below $100 \mu \mathrm{M} I \mathrm{Q}-143$, the activities were even higher compared to those of the control group.

developed and well-established in vitro test system $[15,34,35]$. Only at high concentrations of IQ-143 (100 $\mu \mathrm{M})$ was inhibition apparent: CYP $3 \mathrm{~A} 4$ is strongly inhibited (Table 7; Figure S3 in Additional file 1); and two other enzymes are partially inhibited, CYP2C19 only slightly (5\% loss of activity) and CYP2D6 moderately (40\% loss of activity).

Human cells and staphylococcal cells show only few differences in their core enzyme composition of primary metabolism. For the human cell model the enzymes were compared in both organisms according to the KEGG database, extended by our own sequence analysis (Tables S1 and S4 in Additional file 1). After taking minor differences into account, we assumed as a worstcase scenario that the effects (and metabolic or gene expression changes) of IQ-143 administration in staphylocci are comparable to those in human cells. We thus applied similar constraints (gene expression changes for key enzymes) to the modified metabolic model for the human cells. To the human model we also added the detoxification pathways of the six human CYP enzymes. Applying the constraints apparent for no, low $(1 \mu \mathrm{M}$ or $10 \mu \mathrm{M})$, or high concentrations of IQ-143 $(100 \mu \mathrm{M})$ three CYP enzymes partially or fully inhibited - we tested next whether this is predicted to affect other pathway fluxes in the human cell model (for calculations see Materials and methods). With the exception of the partial block of the cytochrome isoenzymes at high concentrations of IQ-143, there was no other block predicted for any of the other pathways modeled. In accordance with the experimental observations, this would imply low toxicity of IQ-143 in cell culture.

\section{Discussion}

\section{Modeling adaptation processes}

There is an urgent need to find new antibiotics against staphylococci due to the emergence and alarming spread of resistant strains not only in hospitals but, more 
recently, also in the community. In particular, drugs belonging to novel chemical classes are of broad interest as it is assumed that resistance development against such substances will be minimized. In addition, the identification of novel targets may accelerate the finding of new lead substances combating multi-drug-resistant pathogens [36]. The compound IQ-143 has no cytotoxic effects at low concentrations in human cells compared to other isoquinoline compounds. In this study, we have included systems-wide approaches coupled with bioinformatic modeling and host-detoxification enzyme effects to elucidate the mode of action of the antimicrobial compound IQ-143 in different staphylococci; it shows direct application of systems biology in antibiotic research [37].

Our combination of theoretical modeling, analysis of enzyme activity, measurement of metabolite concentrations as well as the incorporation of gene expression data allowed us to describe in large-scale models the diverse effects of the antibiotic compound IQ-143 on the metabolism of both pathogens (S. aureus and S. epidermidis) and human host cells. These approaches are complementary to each other: direct toxicity data were only partially available and metabolite measurements covered only a range of nucleotides, including NAD $(\mathrm{P})$ $(\mathrm{H})$. Our work demonstrates how metabolic modeling can help to fill in missing information and how this allows predictions on the enzyme activities of the complete network, which subsequently can be verified by the experimental measurements. As a requirement for the modeling, the genome sequences were partly reannotated.

Such a combined approach is of general use in metabonomics [33] to model, for instance, the effects of various different isoquinolines and other drugs, the effects of genetic mutations, or even more complex interactions between hosts and pathogens (for example, the metabolism of $S$. aureus under persistence in the host).

Our results suggest that IQ-143 targets the energy metabolism of S. epidermidis and S. aureus (Table 4) and we observed severely limited growth of $S$. epidermidis and S. aureus when IQ-143 was applied. On the other hand (as shown by array data here), gene expression for DNA and RNA polymerases was not downregulated by IQ-143, but was instead up-regulated (up to two-fold). Our modeling can explain both findings. IQ-143 does not affect the DNA and RNA polymerase chain as initially suspected (Table 2), but rather interferes with the energy metabolism.

An example is mode 102, which consists of a pyruvate-phosphotransferase and a PEP-carboxylase. The activity of this particular mode is reduced by one-half after administration of IQ-143 in both staphylococci strains. In general, the metabolism of sugars and alcohols is reduced by IQ-143 and the investigated pathogens counteract this effect by expressing more DNA and RNA polymerases (and other enzymes) in order to maintain appropriate turnover in these pathways.

The general stress response is not strongly activated in S. epidermidis after administration of IQ-143 (only two genes are turned on). Several ABC transporter genes, which probably encode multiple drug efflux pumps, are turned on in the presence of IQ-143. These are typical responses of $S$. epidermidis against toxic agents [38]. However, for IQ-143 the specific pathway effects are more important and stronger.

\section{Metabolic implications}

By analyzing CYP enzyme activity, this study enables the inhibitory potential of IQ-143 towards the major human drug metabolizing CYP enzymes to be assessed. In contrast to several previously tested naphthylisoquinoline alkaloids [15], which showed extraordinarily strong and selective inhibition of CYP2D6, IQ-143 did not show a remarkable inhibition of CYP2D6 or other tested isoenzymes at the relevant concentrations of 1 and $10 \mu \mathrm{M}$. Owing to the low inhibitory activity of the compound, the possibility of drug-drug interactions is very small. Even for CYP3A4, the major human CYP isoenzyme in the gut and liver, inhibition is unlikely because its activity is significantly reduced only at a concentration of $100 \mu \mathrm{M}$, which will not be achieved in the human body. This also reveals that certain structural characteristics might be avoided when developing new drugs from IQ143 in order to minimize toxic effects occurring through protein inhibition.

The two investigated Staphylococcus species use NAD $(\mathrm{H})$ as an energy source for oxidative phosphorylation. In accordance with this, the results of metabolite measurements show lower concentrations of $\mathrm{NAD}^{+}$and NADH. However, NADPH levels increased at the highest concentrations of IQ-143. Therefore, we believe that NADPH-producing enzymes (for example, of the pentose-phosphate pathway) and NADH-producing enzymes (including glyceraldehyde-3P-dehydrogenase, which can use both NADH as well as NADPH) are probably not the primary targets of the inhibition. Instead, IQ-143 has to directly affect NADH consumption. By inhibiting complex 1 of oxidative phosphorylation, NADH consumption is severely affected even at low concentrations of IQ-143; NADH is consumed at a significantly reduced rate, which leads to a smaller quantity of available $\mathrm{NAD}^{+}$. Glyceraldehyde-3P-dehydrogenase, however, is not affected by this, and nor are the NADPH-using enzymes. As modeling shows, this leads to much higher production of NADPH since less and less $\mathrm{NAD}^{+}$is available. 
Our theory is supported by experimental findings (see 'Results: Pathway effects of different concentrations of IQ-143 in S. epidermidis and S. aureus' as well as Tables 5 and 6) and data from the literature. Aromatic substances with a quaternary nitrogen, such as the quinolinium-derived drug dequalinium chloride, tend to accumulate in mitochondria [39,40]. Also, the interference of the mitochondrial respiratory chain, especially complex I, by quaternary isoquinoline derivatives such as $N$-methylisoquinolinium ions or $N$-methyl-1,2,3,4-tetrahydroisoquinoline is well known [41,42]. Since IQ-143 is structurally related to dequalinium chloride, interaction of this newly identified antimicrobial compound with the mitochondrial respiratory chain is possible. Additionally, our findings are supported by the results in Table 5, which lists the changes in nucleotide concentrations after application of IQ-143 to S. aureus. Whereas $0.16 \mu \mathrm{M}$ IQ-143 reduced the AMP concentration by approximately $70 \%$ (control, $0.42 \mu \mathrm{g} / \mathrm{ml}$; $0.16 \mu \mathrm{M}$ IQ-143, $0.12 \mu \mathrm{g} / \mathrm{ml}$ ), an almost 50 -fold increase in AMP concentration was observed using a concentration of $1.25 \mu \mathrm{M}$ IQ-143 (Table 5). Increased AMP concentration due to a breakdown of the labile ATP molecule can be excluded because the control incubation was processed in the same way as the samples treated with IQ-143. Presumably, the accumulation of AMP points to direct inhibition of NADH oxidation by complex I of the respiratory chain because blocking electron transport leads directly to the breakdown of the chemoosmotic potential and, subsequently, oxidative phosphorylation.

The effects of secondary metabolites of the compound, host-pathogen interactions and more complex system effects have not been investigated in this work. However, since the first mouse experiments suggested that IQ-143 is toxic, this substance should currently only be considered as a lead structure for future drug development based on the promising results regarding antibiosis in staphylococci and to negate toxic effects in the host. Certainly this theoretical suggestion requires further experimental tests.

\section{Conclusions}

Utilizing our model, the apparent bacteriostatic and, at higher concentrations, bactericidal effects of IQ-143 in $S$. aureus and S. epidermidis can now be described in detail according to its effects on the activity of specific enzymes and pathways in these organisms, in particular on energy metabolism and DNA/RNA elongation. IQ143 administration affects oxidative phosphorylation but also has an impact on purine metabolism, including direct effects on purine metabolism and other nucleotide-producing enzymes at higher concentrations as well as pathway effects observable, for example, in glycolysis.
These effects can be explained by the drug interfering with the $\mathrm{NAD}(\mathrm{H})$ pool and the multi-enzyme complexes of oxidative phosphorylation. The network effects can only be seen through modeling since measurements of metabolites are able to show only a small part of the whole metabolome. The metabolic effects are also not observable in the gene expression data either unless they lead to significant changes in gene expression. By applying data gathered from the metabolite measurements, the models can be fitted and thus made more accurate than when based on gene expression data alone.

This permits improvement of the lead substance (for example, pro-drug or testing of further modifications). Our combination of modeling and experimental data is generally suited to elucidate organism-wide metabolic adaptations to xenobiotics in a comparative way. Future extensions will include further data sets, such as additional data on toxicity and enzyme kinetics.

\section{Materials and methods \\ Microarray analysis}

Total RNA was isolated from S. epidermidis strain RP62A grown in the presence of $0.16 \mu \mathrm{M}$ (one-quarter of the minimal inhibitory concentration) and $1.25 \mu \mathrm{M}$ (twice the minimal inhibitory concentration) IQ-143 and without the drug. For the analysis of gene expression with subinhibitory concentrations of IQ-143, an overnight culture of $S$. epidermidis RP62A was diluted to an optical density $\mathrm{OD}_{600 \mathrm{~nm}}$ of 0.05 in a $50 \mathrm{ml}$ flask. To this culture $0.16 \mu \mathrm{M}$ IQ-143 was added and the culture was grown with agitation $(200 \mathrm{rpm})$ until $\mathrm{OD}_{600 \mathrm{~nm}}$ reached 1.0. To analyzing the impact of inhibitory concentrations of IQ-143, $1.25 \mu \mathrm{M}$ of the substance was added to the cultures in the exponential growth phase $\left(\mathrm{OD}_{600 \mathrm{~nm}}\right.$ of 1.0) and the cultures were grown for an additional 10 minutes. Bacteria were harvested with the addition of RNA Protect (QIAGEN, Hilden, Germany) according to the manufacturer's instructions. Prior to RNA isolation, bacteria were lysed using glass beads in a Fast Prep shaker (Qbiogene, Heidelberg, Germany) for $45 \mathrm{~s}$ at a speed of 6.5 units. RNA was isolated using a QIAGEN RNeasy kit according to the standard QIAGEN RNeasy protocol.

S. epidermidis RP62A full genome microarrays containing PCR products of 2,282 genes/open reading frames were used for microarray analysis (Scienion, Berlin, Germany). DNA expression data have been deposited in the public databank repository Protecs $[43,44]$ (accession [PROTECS:IQ-143]).

Total RNA $(10 \mu \mathrm{g})$ for DNA microarray analysis isolated from cultures in the exponential growth phase was used for reverse transcription and fluorescent labeling reactions using random primers and Superscript III reverse transcriptase (Invitrogen, Darmstadt, Germany). 
cDNA was concomitantly labeled using the dyes Cy3 and Cy5 according to the manufacturer's instructions (Scienion, Dortmund, Germany). RNA obtained from twelve $(0.16 \mu \mathrm{M})$ and six $(1.25 \mu \mathrm{M})$ different biological experiments was utilized, and a reverse labeling (dye switch) experiment was performed to minimize bias due to differential dye bleaching or incorporation of the Cy3 and $\mathrm{Cy} 5$ dyes during the reverse transcription reaction. Microarray hybridization $\left(16 \mathrm{~h}\right.$ at $\left.50^{\circ} \mathrm{C}\right)$ and washing of the slides were performed according to the manufacturer's instructions. Hybridized slides were scanned using a Genepix 4000B laser scanner (Axon Instruments Inc., Union City, CA, USA). Bioinformatic analyses on the slide hybridization results of each single experiment were performed using Genepix Pro3.0 (Axon Instruments Inc.). Data for each image were normalized to the mean ratio of means of all features.

\section{Reconstruction of metabolic networks}

To model involved metabolic pathways, we used the KEGG database [24]. Additional genome annotation of missing enzyme activities for the central pathways was determined using iterative sequence and domain analysis methods [19]. Subsequent experimental verification by PCR complemented this (Tables S1, S2, S3, and S4, and Figure S6 in Additional file 1). The model of central metabolism included lipid, amino acid, and central carbohydrate metabolism as well as nucleotide and salvage pathways.

\section{Metabolic flux modeling}

Extreme pathways possible in the annotated enzyme network were calculated first [24]. To identify actual flux strengths, we used YANAsquare $[21,22]$ and a custom written program in $\mathrm{R}$ [23]. We modeled flux strengths in the metabolic webs of $S$. aureus USA300 and S. epidermidis RP62A according to gene expression data obtained for the purpose (Tables S5 and S6 in Additional file 1). A least square fit used first YANAsquare and next the improved $R$ routine to calculate optimal pathway fluxes that best matched the constraints for key enzyme activities as estimated according to significant elevated or lowered enzyme expression in the above data sets (Table 1; Tables S5 and S6 in Additional file 1). Additional metabolite measurements (Figures 7 and 8 ) probed whether the metabolite concentrations were correctly predicted. Measured CYP activity data were considered next in the model to test whether inhibition of CYP enzymes affected other pathways in their fluxes.

Detailed input files for the pathway models are provided in Additional file 1 (for $S$. aureus USA300 in Table S2; for S. epidermidis RP62A inTable S3). The calculated activities of the different extreme pathway modes for no IQ-143 and two different concentrations of it are listed in Tables S7, S8, and S9 (S. aureus), S10, S11, and S12 (S. epidermidis), and S12, S13, S14, and S15 (human).

\section{Cell culture}

Cells of S. aureus USA300 and S. epidermidis RP62A were cultured in Luria-Bertani-Medium at $30^{\circ} \mathrm{C}$ and shaken at $170 \mathrm{rpm}$. After 2 hours, IQ-143 was added: $0.8 \mu \mathrm{l}$ of a $20 \mathrm{mM}$ stock solution of IQ-143 in dimethyl sulfoxide was added per $100 \mathrm{ml}$ cell culture to attain a concentration of $0.16 \mu \mathrm{M}$. For a concentration of 1.25 $\mu \mathrm{M}, 6.25 \mu \mathrm{l}$ per $100 \mathrm{ml}$ cell culture were added. The cells were harvested when an OD of 1.0 was reached and the metabolites were extracted. Toxicity assays in human cells were conducted according to [15]. Concentrations tested included $0.16 \mu \mathrm{M}$ and $1.25 \mu \mathrm{M}$ IQ-143, and a control with no antibiotic added.

\section{In vitro inhibitory activity of IQ-143 on CYP enzymes}

To test the inhibitory activity of IQ-143 on the six main human drug-metabolizing CYP enzymes, we applied the method described by Unger and Frank [34]. The enzymes CYP1A2, 2C8/2C9/2C19, 2D6 and 3A4 were derived from baculovirus-infected insect cells and were incubated with different concentrations of IQ-143 (1, 10 , and $100 \mu \mathrm{M})$.

\section{$\mathrm{IC}_{50}$ determination for human cells}

J774.1 macrophages were cultured in complete medium (RPMI with $\mathrm{NaHCO}_{3}, 10 \%$ fetal calf serum, $2 \mathrm{mM}$ glutamine, $10 \mathrm{mM}$ Hepes pH 7.2, $100 \mathrm{U} / \mathrm{ml}$ penicillin, $50 \mu \mathrm{g} /$ $\mathrm{ml}$ gentamicin, $50 \mu \mathrm{M}$ 2-mercaptoethanol) without phenol red in the absence or presence of increasing concentrations of the compounds at a cell density of $1 \times 10^{5}$ cells $/ \mathrm{ml}(200 \mu \mathrm{l})$ for $24 \mathrm{~h}$ at $37^{\circ} \mathrm{C}, 5 \% \mathrm{CO}_{2}$ and $95 \%$ humidity. Following the addition of $20 \mu \mathrm{l}$ of Alamar Blue, the plates were incubated and the ODs measured at $24 \mathrm{~h}, 48 \mathrm{~h}$, and $72 \mathrm{~h}$. The standard Alamar blue assay was performed as previously described [45].

Kidney epithelial $293 \mathrm{~T}$ cells $\left(2 \times 10^{4}\right.$ cells $\left./ \mathrm{ml}\right)$ were tested in the same manner as the macrophages except that complete DMEM medium was used: $4.5 \mathrm{~g} / \mathrm{l}$ solution of DMEM high D-glucose solution with sodium pyruvate but without L-glutamine, fetal bovine serum superior at a final concentration of $20 \%, 200 \mathrm{mM} \mathrm{L}$-glutamine 100x.

\section{Commercial sources of standards for the metabolite measurements}

The standards were obtained from the following suppliers. AppliChem (Darmstadt, Germany): $\beta$-nicotinamide adenine dinucleotide (NAD), $\beta$-nicotinamide adenine dinucleotide phosphate sodium salt (NADP), $\beta$-nicotinamide 
adenine dinucleotide reduced dipotassium salt (NADH), and $\beta$-nicotinamide adenine dinucleotide 2'-phosphate reduced tetrasodium salt (NADPH). Sigma (Taufkirchen, Germany): adenosine 5'-monophosphate sodium salt, cytidine 5'-monophosphate disodium salt, dextromethorphan, imipramine, inosine 5'-monophosphate disodium salt, guanosine 5'-monophosphate disodium salt hydrate, midazolam, paclitaxel, reserpine, tacrine, tolbutamide, thymidine 5'-monophosphate disodium salt hydrate, xanthosine 5'-monophosphate disodium salt, and sodium chloride. Fluka (Buchs, Switzerland): tributylamine and formic acid (purissimum grade). Fisher Scientific (Schwerte, Germany): methanol and acetonitrile. Natutec (Frankfurt, Germany): recombinant CYP1A2, CYP2C8, CYP2C9, CYP2C19, CYP2D6 and CYP3A4 from baculovirus-infected insect cells co-expressed with $\mathrm{P} 450$ reductase and cytochrome b5.

\section{Cell culture harvesting and HPLC}

Cultivated cells (S. aureus and S. epidermidis) were quenched by adding methanol $50 \%(\mathrm{v} / \mathrm{v})$. After washing the cell pellet with $0.9 \%$ sodium chloride it was extracted with methanol $80 \%(\mathrm{v} / \mathrm{v})$ by means of ultrasonic treatment. After centrifugation the supernatants were directly analyzed by HPLC using an Agilent System 1100 LC (Waldbronn, Germany) consisting of a vacuum degasser, a binary pump, an autosampler, a thermostatted column compartment and an UV-visible diode array detector. System control and data processing were performed using the Agilent ChemStation Software revision A.10.01.

\section{Determination of purine and pyrimidine nucleotides (CMP, AMP, IMP, GMP, TMP and XMP)}

The HPLC methods for the analysis of the purine and pyrimidine nucleotides were adapted from Schmitz et al. [46]. A sample volume of $10 \mu \mathrm{l}$ was injected onto a 150 $\times 4.6 \mathrm{~mm}$ internal diameter, $4 \mu \mathrm{m}$ Synergi Fusion RP column (Phenomenex, Aschaffenburg, Germany). The mobile phase consisted of water (A) and acetonitrile (B), both containing $5 \mathrm{mM}$ tributylamine and $0.1 \%$ formic acid. The following gradient (percentage B) was applied: 0 to 5 minutes, $5 \%$; 15 minutes, $20 \%$; 18 minutes, $20 \%$. After 18 minutes the column was flushed with 100\% B for 3 minutes and re-equilibrated with $5 \% \mathrm{~B}$. The flow rate was set to $1 \mathrm{ml} /$ minute and the temperature for the column was set to $25^{\circ} \mathrm{C}$. As all nucleotides show high UV absorption at about $260 \mathrm{~nm}$, this wavelength was chosen for detection. All measurements were performed in triplicate. The external calibration for quantification was carried out through measurement of a mixture of the corresponding nucleotides covering a range between 0.5 and $100 \mu \mathrm{g} / \mathrm{ml}$.

\section{Determination of nicotinamide derivatives (NAD, NADH, NADP, NADPH)}

For the HPLC analysis of the nicotinamide derivatives the same method as described for the nucleotides was applied. However, the gradient (percentage B) was slightly varied: 0 to 5 minutes, 5\%; 15 minutes, 50\%; 18 minutes, $50 \%$. After 18 minutes the column was flushed with $100 \%$ B for 3 minutes and re-equilibrated with $5 \%$ B.

\section{Statistical analysis}

Statistical analysis was performed using the Mann-Whitney U-test by means of the software Statistica 8.0 (StatSoft (Europe) GmbH, 20253 Hamburg, Germany); Pvalues were calculated in relation to corresponding controls (pooled values).

\section{Additional data and scripts}

As well as Additional file 1, other files are available from [47], containing: an introduction to pathway modeling in general and a tutorial for working with YANAsquare; input files for YANAsquare needed to calculate the extreme modes; scripts for $\mathrm{R}$ for calculation of the effects of changing gene expression after administration of IQ-143 (these are also used for a statistical evaluation of said effects); and scripts for PERL to import the results from $\mathrm{R}$ to YANAsquare.

\section{Additional material}

Additional file 1: Supplementary materials. Additional file 1 is a Word document containing additional data on sequence comparisons, pathway models, synthesis and effects of the IQ-143 compound, gene expression data, and nucleotide and NAD measurements, as reported in the manuscript.

\section{Abbreviations}

ABC: ATP-binding cassette; CMP: cytidine-5'-monophosphate; CYP: cytochrome P450; DMEM: Dulbecco/Vogt modified Eagle's minimal essential medium; HPLC: high-performance liquid chromatography; IMP: inosine monophosphate; IQ: isoquinoline; IQ-143: synthetic analogue of the noveltype $\mathrm{N}$ :C-coupled naphthyl-isoquinoline alkaloid ancisheynine; KEGG: Kyoto Encyclopedia of Genes and Genomes; OD: optical density; PCR: polymerase chain reaction; SERP: Staphylococcus epidermidis RP62A;TMP: thymidine-5'monophosphate; XMP: xanthosine-5'-monophosphate.

\section{Acknowledgements}

We thank the German Research Council (Deutsche Forschungsgemeinschaft DFG), grants SFB630 (projects A1, A2, B5, C6 and Z1), the Fonds der Chemischen Industrie (fellowship to TG), and the Hochschul- und Wissenschaftsprogramm of the University of Würzburg (fellowship to TG), Da 208/10-1 (fellowship to CL) and TR34/A8 (fellowship to CL) and the State of Bavaria for funding, as well as our colleagues from the SFB630 for stimulating discussions. We also thank Svitlana Kozytska and Elena Katzowitsch for technical assistance and Wilma Ziebuhr for helpful discussions.

\section{Author details}

${ }^{1}$ University of Würzburg, Theodor-Boveri Institute, Department of Bioinformatics, Am Hubland, 97074 Würzburg, Germany. ${ }^{2}$ University of 
Würzburg, Institute for Pharmacy and Food Chemistry, Am Hubland, 97074 Würzburg, Germany. ${ }^{3}$ University of Würzburg, Institute for Molecular Infection Biology, Josef-Schneider-Straße 2, 97080 Würzburg, Germany. ${ }^{4}$ Ernst-MoritzArndt University, Institute for Microbiology, Greifswald, Friedrich- LudwigJahn- Straße 15, 17487 Greifswald, Germany. ${ }^{5}$ University of Würzburg, Institute for Organic Chemistry, Am Hubland, 97074 Würzburg, Germany. ${ }^{6}$ Present address: RWTH Aachen, Institute of Organic Chemistry, Landoltweg 1, 52074 Aachen, Germany. ${ }^{7}$ EMBL Heidelberg, BioComputing Unit, Meyerhofstraße 1, 69117 Heidelberg, Germany.

\section{Authors' contributions}

AC did the genome re-annotation, the set up and calculation of the different metabolic models, culturing and harvesting of cells and was involved in data analysis of all data sets. CR conducted all metabolite measurements and cytochrome assays, and was involved in data analysis. $\mathrm{CL}$ was involved in programming tasks (PERL/R) and JB in database management (Protecs). KO did all gene expression analysis experiments and provided infection biology expertise. TAO did all cell toxicity tests. TG and GB selected and synthesized IQs and provided chemical expertise. UH and MU supervised CR and provided pharmaceutical expertise. In addition, MU was involved in the cytochrome assays and led and guided the metabolite measurements. TD led and guided the study, supervised AC, and was involved in the data analysis of all data sets. All authors participated in the writing of the manuscript and approved its final version.

\section{Competing interests}

The authors declare that they have no competing interests.

Received: 17 November 2010 Revised: 14 March 2011

Accepted: 21 March 2011 Published: 21 March 2011

\section{References}

1. Grundmann H, Aanensen DM, van den Wijngaard CC, Spratt BG, Harmsen D, Friedrich AW, the European Staphylococcal Reference Laboratory Working Group: Geographic distribution of Staphylococcus aureus causing invasive infections in Europe: a molecularepidemiological analysis. PLoS Med 2010, 7:e1000215.

2. Wright JA, Nair SP: Interaction of staphylococci with bone. Int J Med Microbiol 2010, 300:193-204.

3. Cheng AG, Kim HK, Burts ML, Krausz T, Schneewind O, Missiakas DM: Genetic requirements for Staphylococcus aureus abscess formation and persistence in host tissues. FASEB J 2009, 23:3393-3404.

4. Mattner F, Biertz F, Ziesing S, Gastmeier P, Chaberny IF: Long-term persistence of MRSA in re-admitted patients. Infection 2010, 38:363-371.

5. Coen M: A metabonomic approach for mechanistic exploration of preclinical toxicology. Toxicology 2010, 278:326-340.

6. Papin JA, Stelling J, Price ND, Klamt S, Schuster S, Palsson BO: Comparison of network based pathway analysis methods. Trends Biotechnol 2004, 22:400-405.

7. Vinga S, Neves AR, Santos H, Brandt BW, Kooijman SA: Subcellular metabolic organization in the context of dynamic energy budget and biochemical systems theories. Philos Trans R Soc Lond B Biol Sci 2010, 365:3429-3442.

8. Bartl M, Li P, Schuster S: Modelling the optimal timing in metabolic pathway activation-use of Pontryagin's Maximum Principle and role of the Golden section. Biosystems 2010, 101:67-77.

9. Bringmann G, Gulder T, Reichert M, Meyer F: Ancisheynine, the first N,Ccoupled naphthylisoquinoline alkaloid: Total synthesis and stereochemical analysis. Org Lett 2006, 8:1037-1040.

10. Bringmann G, Kajahn I, Reichert M, Pedersen SHE, Faber JH, Gulder T, Brun R, Christensen SB, Ponte-Sucre A, Moll H, Heubl G, Mudogo V: Ancistrocladinium $A$ and $B$, the first $N, C$-coupled naphthyldihydroisoquinoline alkaloids, from a Congolese ancistrocladus species. J Org Chem 2006, 71:9348-9356.

11. Bringmann $G$, Gulder $T$, Hertlein $B$, Hemberger $Y$, Meyer F: Total synthesis of the $\mathrm{N}, \mathrm{C}$-coupled naphthylisoquinoline alkaloids ancistrocladinium $\mathrm{A}$ and B and related analogues. J Am Chem Soc 2010, 132:1151-1158.

12. Bringmann G, Hertlein-Amslinger B, Kajahn I, Dreyer M, Brun R, Moll $H$, Stich A, Ndjoko loset K, Schmitz W, Hoang Ngoc L: Phenolic analogs of the $N, C$-coupled naphthylisoquinoline alkaloid ancistrocladinium $A$, from
Ancistrocladus cochinchinensis (Ancistrocladaceae), with improved antiprotozoal activities. Phytochemistry 2011, 72:89-93.

13. Yang LK, Glover RP, Yoganathan K, Sarnaik JP, Godbole AJ, Soejarto DD, Buss AD, Butler MS: Ancisheynine, a novel naphthylisoquinolinium alkaloid from Ancistrocladus heyneanus. Tetrahedron Lett 2003, 44:5827-5829.

14. Ponte-Sucre A, Faber JH, Gulder T, Kajahn I, Pedersen SEH, Schultheis M, Bringmann G, Moll H: Activities of naphthylisoquinoline alkaloids and synthetic analogs against Leishmania major. Antimicrob Agents Chemother 2007, 51:188-194.

15. Ponte-Sucre A, Gulder T, Wegehaupt A, Albert C, Rikanovic C, Schaeflein L, Frank A, Schultheis M, Unger M, Holzgrabe U, Bringmann G, Moll H: Structure-activity relationship and studies on the molecular mechanism of leishmanicidal N,C-coupled arylisoquinolinium salts. J Med Chem 2009, 52:626-636.

16. Ponte-Sucre A, Gulder T, Gulder AM, Vollmers G, Bringmann G, Moll H: Alterations on the structure of Leishmania major induced by $N$ arylisoquinolines correlate with compound accumulation and disposition. J Med Microbiol 2010, 59:69-75.

17. Gill SR, Fouts DE, Archer GL, Mongodin EF, Deboy RT, Ravel J, Paulsen IT, Kolonay JF, Brinkac L, Beanan M, Dodson RJ, Daugherty SC, Madupu R, Angiuoli SV, Durkin AS, Haft DH, Vamathevan J, Khouri H, Utterback T, Lee C, Dimitrov G, Jiang L, Qin H, Weidman J, Tran K, Kang K, Hance IR, Nelson KE, Fraser CM: Insights on evolution of virulence and resistance from the complete genome analysis of an early methicillin-resistant Staphylococcus aureus strain and a biofilm-producing methicillinresistant Staphylococcus epidermidis strain. J Bacteriol 2005, 187:2426-2438.

18. Diep BA, Gill SR, Chang RF, Phan TH, Chen JH, Davidson MG, Lin F, Lin J, Carleton HA, Mongodin EF, Sensabaugh GF, Perdreau-Remington F: Complete genome sequence of USA300, an epidemic clone of community-acquired methicillin-resistant Staphylococcus aureus. Lancet 2006, 367:731-739

19. Gaudermann P, Vogl I, Zientz E, Silva FJ, Moya A, Gross R, Dandekar T: Analysis of and function predictions for previously conserved hypothetical or putative proteins in Blochmannia floridanus. BMC Microbiol 2006, 6:1.

20. Bringmann G, Gulder T, Hentschel U, Meyer F, Moll H, Morschhäuser J, Ponte-Sucre De Vanegas A, Ziebuhr W, Stich A, Brun R, Müller WEG, Mudogo V: Preparation of isoquinolines as antibacterial coating materials. 2007, PCT/EP2007/008440;

21. Schwarz R, Musch P, von Kamp A, Engels B, Schirmer H, Schuster S, Dandekar T: YANA - a software tool for analyzing flux modes, geneexpression and enzyme activities. BMC Bioinformatics 2005, 6:135.

22. Schwarz R, Liang C, Kaleta C, Kühnel M, Hoffmann E, Kuznetsov S, Hecker M, Griffiths G, Schuster S, Dandekar T: Integrated network reconstruction, visualization and analysis using YANAsquare. BMC Bioinformatics 2007, 8:313.

23. Gentleman RC, Ihaka R: R: A Language for data analysis and graphics. J Comp Graph Stat 1996, 5:299-314.

24. Schuster S, Fell DA, Dandekar T: A general definition of metabolic pathways useful for systematic organization and analysis of complex metabolic networks. Nat Biotech 2000, 18:326-332.

25. Kanehisa M, Araki M, Goto S, Hattori M, Hirakawa M, Itoh M, Katayama T, Kawashima S, Okuda S, Tokimatsu T, Yamanishi Y: KEGG for linking genomes to life and the environment. Nucleic Acids Res 2008, 36: D480-D484.

26. Otto M: Staphylococcus epidermidis - the accidental pathogen. Nat Rev Microbiol 2009, 8:555-567.

27. Candela T, Fouet A: Poly-gamma-glutamate in bacteria. Mol Microbiol 2006, 60:1091-1098.

28. Kocianova S, Vuong C, Yao Y, Voyich JM, Fischer ER, DeLeo FR, Otto M: Key role of poly gamma-DL-glutamic acid in immune evasion and virulence of Staphylococcus epidermidis. J Clin Invest 2005, 115:688-694.

29. Lotz GP, Lin H, Harst A, Obermann WM: Aha1 binds to the middle domain of $\mathrm{Hsp} 90$, contributes to client protein activation and stimulates the ATPase activity of the molecular chaperone. J Biol Chem 2003, 278:17228-17235.

30. Panaretou B, Siligardi G, Meyer P, Maloney A, Sullivan JK, Singh S, Millson SH, Clarke PA, Naaby-Hansen S, Stein R, Cramer R, Mollapour M, Workman P, Piper PW, Pearl LH, Prodromou C: Activation of the ATPase 
activity of $\mathrm{Hsp} 90$ by the stress-regulated cochaperone Aha1. Mol Cell 2002, 10:1307-1318.

31. Lange $\mathrm{H}: \mathrm{ABC}$-transporters: implications on drug resistance from microorganisms to human cancers. Int I Antimicrob Agents 2003, 22:188-199.

32. Götz F, Otto M: ABC transporters of staphylococci. Res Microbiol 2001, 152:351-356.

33. Nicholson JK: Global systems biology, personalized medicine and molecular epidemiology. Mol Syst Biol 2006, 2:52.

34. Unger $M$, Frank $A$ : Simultaneous determination of the inhibitory potency of herbal extracts on the activity of six major cytochrome P450 enzymes using liquid chromatography/mass spectrometry and automated online extraction. Rapid Commun Mass Spectrom 2004, 18:2273-2281.

35. Frank $A$, Unger M: Analysis of frankincense from various Boswellia species with inhibitory activity on human drug metabolising cytochrome P450 enzymes using liquid chromatography mass spectrometry after automated on-line extraction. J Chromatogr A 2006, 1112:255-262.

36. French $\mathrm{GL}$ : The continuing crisis in antibiotic resistance. Int J Antimicrob Agents 2010, 36(Suppl 3):S3-7.

37. Dandekar T, Dandekar G: Pharmacogenomic strategies against microbial resistance: from bright to bleak to innovative. Pharmacogenomics 2010, 11:1193-1196.

38. Putmann $\mathrm{M}$, van Veen HW, Konings WN: Molecular properties of bacterial multidrug transporters. Microbiol Mol Biol Rev 2000, 64:672-693.

39. Chen LB: Mitochondrial membrane potential in living cells. Annu Rev Cell Biol 1988, 4:155-181.

40. Weiss MJ, Wong JR, Ha CS, Bleday R, Salem RR, Steele GD Jr, Chen LB: Dequalinium, a topical antimicrobial agent, displays anticarcinoma activity based on selective mitochondrial accumulation. Proc Natl Acad Sci USA 1987, 84:5444-5448

41. Suzuki $K$, Mizuno $Y$, Yamauchi $Y$, Nagatsu T, Mitsuo $Y$ : Selective inhibition of complex I by $\mathrm{N}$-methylisoquinolinium ion and $\mathrm{N}$-methyl-1,2,3,4tetrahydroisoquinoline in isolated mitochondria prepared from mouse brain. J Neurol Sci 1992, 109:219-223.

42. McNaught KS, Thull U, Carrupt PA, Altomare C, Cellamare S, Carotti A, Testa B, Jenner P, Marsden CD: Inhibition of complex I by isoquinoline derivatives structurally related to 1 -methyl-4-phenyl-1,2,3,6tetrahydropyridine (MPTP). Biochem Pharmacol 1995, 50:1903-1911.

43. Fuchs S, Mehlan H, Kusch H, Teumer A, Zühlke D, Berth M, Wolf C, Dandekar T, Hecker M, Engelmann S, Bernhardt J: Protecs, a comprehensive and powerful storage and analysis system for OMICS data, applied for profiling the anaerobiosis response of Staphylococcus aureus COL. Proteomics 2010, 10:2982-3000.

44. Protecs. [http://microbio1.biologie.uni-greifswald.de/csp/bio/login.csp].

45. Pimentel-Elardo SM, Kozytska S, Bugni TS, Ireland CM, Moll H, Hentschel U: Anti-parasitic compounds from Streptomyces sp. strains isolated from mediterranean sponges. Mar Drugs 2010, 8:373-380.

46. Schmitz V, Klawitter J, Leibfritz D, Christians U: Development and validation of an assay for the quantification of 11 nucleotides using LC/ LC-electrospray ionization-MS. Anal Biochem 2007, 365:230-239.

47. Biozentrum Universität Würzburg: IQ-143. [http://iq143.bioapps. biozentrum.uni-wuerzburg.de].

48. Altschul SF, Madden TL, Schaffer AA, Zhang J, Zhang Z, Miller W, Lipman DJ: Gapped BLAST and PSI-BLAST: a new generation of protein database search programs. Nucleic Acids Res 1997, 25:3389-3402.

49. Bringmann $G$, Gulder T, Hentschel U, Meyer F, Moll H, Morschhäuser J, Ponte-Sucre A, Ziebuhr W, Stich A, Brun R, Müller WEG, Mudogo V: Biofilmhemmende Wirkung sowie anti-infektive Aktivität $N, C$-verknüpfter Arylisochinoline, deren pharmazeutische Zusammensetzung und deren Verwendung. Patentschrift. 2007, 2007, DE 102006046 922B3.

doi:10.1186/gb-2011-12-3-r24

Cite this article as: Cecil et al:: Modeling antibiotic and cytotoxic effects of the dimeric isoquinoline IQ-143 on metabolism and its regulation in Staphylococcus aureus, Staphylococcus epidermidis and human cells. Genome Biology 2011 12:R24.

\section{Submit your next manuscript to BioMed Central and take full advantage of:}

- Convenient online submission

- Thorough peer review

- No space constraints or color figure charges

- Immediate publication on acceptance

- Inclusion in PubMed, CAS, Scopus and Google Scholar

- Research which is freely available for redistribution

Submit your manuscript at www.biomedcentral.com/submit
Biomed Central 